\title{
CINE NAZI EN URUGUAY (1933-1945): PRIMEROS APUNTES SOBRE DISTRIBUCIÓN, EXHIBICIÓN Y RECEPCIÓN
}

\author{
Nazi Cinema in Uruguay (1933-1945): \\ First Notes about Distribution, Exhibition and Reception \\ GERMÁN SILVEIRA $^{\mathrm{a}}$ \\ GESTA (EI- CSIC-Udelar)
}

DOI: $10.15366 /$ secuencias 2020.52 .006

\begin{abstract}
RESUMEN
Entre 1933 y 1945, un número importante de películas alemanas de ese período llegó a Uruguay, pero se sabe muy poco sobre las características de la distribución, la exhibición y su recepción. Este artículo propone un relevamiento de las películas que se estrenaron en Montevideo durante aquellos años, así como una primera aproximación a la distribución en las salas comerciales y a la recepción crítica en la revista Cine Radio Actualidad. Son los primeros apuntes sobre un tema inexplorado en el país a nivel académico, que tienen el propósito de ayudar a comprender mejor la dimensión que alcanzó la propaganda nazi en la región.
\end{abstract}

Palabras clave: Uruguay, cine nazi, estrenos, Cine Radio Actualidad, crítica cinematográfica.

\begin{abstract}
Between 1933 and 1945, a significant number of German films arrived in Uruguay. Nevertheless, very little it is known about the circumstances of their distribution, exhibition, and reception. This article proposes a survey of the films produced by the Third Reich that were released in Montevideo during those years. The aim is, as well, to set out a first approach to their distribution in commercial theaters and to their critical reception in Cine Radio Actualidad magazine. Thus, the article presents the first notes on an unexplored topic in Uruguay, which are intended to provide a better understanding of the dimension that Nazi propaganda reached in the region.
\end{abstract}

Keywords: Uruguay, Nazi Cinema, Premieres, Cine Radio Actualidad, Film Criticism.

[a] Germán Silveira es Doctor en Estudios Transculturales por la Universidad Jean Moulin Lyon 3. Es miembro del Grupo de Estudios Audiovisuales (GESTA), donde codirige la línea de investigación: «Los discursos sobre el cine uruguayo». Integra el Sistema Nacional de Investigadores (SIN-ANII), Uruguay, desde 2015. Sus áreas de investigación, sobre las que ha publicado diversos artículos en revistas especializadas, refieren al discurso de la crítica cinematográfica, la historia de la cultura cinematográfica, la recepción y los públicos. Es autor del libro Cultura y cinefilia. Historia del público de la Cinemateca Uruguaya (Montevideo, Cinemateca Uruguaya, 2019). E-mail: gsilveira72@gmail.com.. 


\section{Presentación ${ }^{1}$}

El presente artículo se propone analizar la exhibición del cine alemán durante los años del Tercer Reich (1933-1945) en salas de cine de Uruguay con el objetivo de aportar una mejor comprensión al alcance y las características de la distribución de la industria cinematográfica en tiempos del nazismo en América del Sur. El tema carece de antecedentes en el campo académico en Uruguay, por lo tanto, se trata de una primera aproximación a algunos de los archivos, fuentes y documentos disponibles en relación con la distribución, exhibición y recepción del cine de ideología nazi en este país.

El corpus seleccionado se circunscribe a las películas alemanas de largometraje exhibidas entre los años 1933 y 1945, en salas del circuito comercial de la ciudad de Montevideo. La distribución de cortometrajes, así como la exhibición en el circuito de salas localizadas en otras ciudades del país que funcionaban en esos años -hoy en su mayoría cerradas-, quedan excluidas del presente análisis. El relevamiento de las películas estrenadas en Montevideo aportará así una visión de conjunto al cine que se distribuyó en la capital. A partir de la teorización sobre cine nazi realizada por algunos autores, se agruparán estas películas por género cinematográfico con el fin de dar cuenta de la diversidad de la producción alemana que llegó hasta Uruguay y que el imaginario común asocia generalmente con un cine documental de propaganda.

Para detectar los estrenos en Montevideo durante la época seleccionada, se recurrió, por un lado, a la base de datos en línea construida por el crítico Osvaldo Saratsola a partir de todos los films estrenados en salas de la ciudad desde $1929^{2}$. Este catálogo permitió realizar la búsqueda por país (Alemania) y, a la vez, discriminar por año de estreno. De este modo surgió un listado de películas de origen alemán estrenadas entre 1933 y 1945, poniendo atención en el lugar y año de producción para verificar que pertenecieran al período subsiguiente a la llegada de Hitler a la cancillería (en enero de 1933). Paralelamente, en la biblioteca especializada del Archivo Nacional de la Imagen y la Palabra del SODRE (Servicio Oficial de Difusión, Representaciones y Espectáculos) se consultaron algunos programas de la época y se comenzó a mapear los estrenos alemanes en los números de la revista Cine Radio Actualidad correspondientes a esos años, cuya guía de estrenos daba cuenta de la cartelera semanal en Montevideo ${ }^{3}$. Una vez relevados los estrenos en Uruguay, el artículo se propone repasar las primeras reseñas publicadas en la revista Cine Radio Actualidad, creada en 1936, sobre las películas alemanas que se exhibían entonces en los cines de la capital. Esta revista marcó el camino de la crítica de cine independiente en el país, por lo que resulta pertinente repasar la posición estética, política y ética que adoptan los críticos de la publicación cuando, antes de la Segunda Guerra Mundial, se enfrentan al cine alemán del período nazi.

En la Alemania del Tercer Reich, la industria cinematográfica pasa tempranamente a estar al servicio de la propagación, tanto directa como más sutil, de la ideología nacionalsocialista. Además de documentales de propaganda, durante el régimen nazi se produjeron películas de entretenimiento de los más diversos géneros. En Hitler's Hollywood (2017), Rüdiger Suchsland señala que durante el Tercer Reich se produjeron más de mil películas, de las cuales alrededor de quinientas fueron comedias y musicales (operetas). El director también identifica unos trescientos melodramas, además de films de aventuras y retratos de personalidades históricas poco fieles a la historia, entre otros géneros y subgéneros ${ }^{4}$.
[1] N. del E. Los títulos de las películas que se citan en castellano a lo largo del texto corresponden a los de estreno en Uruguay.

[2] Cinestrenos. El cine en Montevideo desde 1929. Disponible en: <http://www.uruguaytotal. com/estrenos/>

[3] Esto permitió corregir algún error encontrado en la base de datos en línea de Cinestrenos; concretamente, la película Juana, el húsar negro de Johannes Meyer (Schwarzer Jäger Johanna, 1934), estrenada en Uruguay en 1936. En su lugar aparece Der Schwarze Husar (1932) del director Gerhard Lamprecht, con mismo título en español (Juana, el húsar negro).

[4] De estos géneros da cuenta Rüdiger Suchsland en el documental Hitler's Hollywood (2017), donde rescata fragmentos de muchas de las películas producidas entre 1933 y 1945. 
[5] Mark Jenkins, "Why Forbidden Films Remain Officially Locked Away» (National Public Radio. Movie Reviews, 14 de mayo de 2015). Disponible en: $<$ https://www.npr. org/2015/05/14/405966208/ why-forbidden-films-remain-officially-locked-away> $(10 / 03 / 2020)$.

[6] Virgilio Ilari, «Verbotene Filme I Kriegsfilme del Terzo Reich» (Conference Paper, mayo de 2015). Disponible en: $<$ https://www.researchgate. net/publication/274989203 Verbotene_Filme_I_Kriegsfilme_ del_Terzo_Reich > $(12 / 03 / 2020)$.

[7] John Frank Kelson y Kenneth R. M. Short (eds.): Catalogue of Forbidden German Feature and Short Film Productions: Held in Zonal Film Archives of Film Section (Information Services Division. Control Commission for Germany, Trowbridge, Flicks Books, 1996).

[8] Agradezco a la investigadora Marina Moguillansky, quien me alentó a desarrollar esta línea de investigación sobre cine nazi en Uruguay y me envió las listas de films prohibidos para poder contrastar la información contenida allí durante el trabajo de búsqueda en archivo. También agradezco a la profesora Cecilia Pérez Mondino los intercambios acerca del alcance de la propagación del nacionalsocialismo en Uruguay.

[9] Información tomada del sitio web de Fundación Murnau. Disponible en: <https://www. murnau-stiftung.de/filmbestand $>(16 / 04 / 2020)$.

[10] N. del E. Estrenada en España como Quex.

[11] N. del E. Estrenada en España como El judio Suss.

[12] N. del E. Estrenada en España con el mismo título.

[13] Hitlerjunge Quex fue exhibida años más tarde, pero en el marco de un ciclo de cine nazi programado por la Cinemateca Uruguaya en el año 1977.

[14] Gerardo Caetano y José Rilla, Historia contemporánea del Uruguay. De la colonia al siglo XXI (Montevideo, Claeh / Fin de siglo, 2016), p. 216.
Una vez finalizada la Segunda Guerra, en el proceso de de-nazificación y reconstrucción de Alemania, los aliados pusieron especial atención en la producción cinematográfica supervisada por Goebbels y se elaboró un informe que daba cuenta del contenido de todos los films producidos entre 1933 y 1945, con el fin de impedir la difusión de las ideas antisemitas y nacionalsocialistas ${ }^{5}$. El investigador italiano Virgilio Ilari señala que de acuerdo con el informe que el británico John F. Kelson compiló entre 1945 y 1951 para los archivos de la Comisión de Control Aliado (División de Servicios de Información, Sección de Cine) se calcula que un total de 3000 películas fueron realizadas en ese período: unos 2000 cortometrajes y 1094 películas de largometraje ${ }^{6}$. Este catálogo de películas y cortometrajes alemanes prohibidos fue reimpreso en 1996 de manera incompleta por el Imperial War Museum, editado y presentado por Kenneth R. M. Short ${ }^{7}$.

Para la elaboración de este artículo, se tuvieron en cuenta dos listas de películas prohibidas de propaganda e ideología nazi como referencia para detectar la exhibición de estas películas en el circuito de salas montevideanas en las décadas del treinta y cuarenta ${ }^{8}$. La primera lista corresponde al catálogo elaborado por los aliados y editado por Short en 1996. Algunos de los largometrajes que allí figuran fueron estrenados comercialmente entre 1933 y 1945 en Montevideo (se marcan en negrita en el listado de estrenos que se presenta más adelante). La segunda lista fue publicada en 2012 por la Fundación F. W. Murnau en Alemania. La Fundación Murnau, como archivo y titular de derechos, preserva en la actualidad materiales de las antiguas productoras Ufa, Universum Film, Bavaria, Terra, Tobis y Berlin-Film. Se incluyen más de 6000 títulos de la época muda y sonora desde la década de 1890 a la década de 1960. Negativos y copias de películas se encuentran almacenados en blockhaus técnicamente equipados en Wiesbaden, y bajo cuidado fiduciario en el Bundesarchiv-Filmarchiv en Koblenz y Berlin?.

La lista de la Fundación Murnau elaborada en 2012 agrupa un total de cuarenta y cuatro películas sobre las que la institución posee los derechos. A partir de este conjunto de películas de propaganda e ideología nazi, Felix Moëller realizó el documental Verbotene Filme (Forbidden Films, 2013). Allí muestra que hoy esos films se encuentran «bajo reserva» en los archivos y no pueden exhibirse públicamente debido a sus mensajes abiertamente racistas, antisemitas o de glorificación de la guerra. Entre los títulos figuran, por ejemplo, Hitlerjunge Quex (Hans Steinhoff, 1933) ${ }^{10}$, Jud Suss (Veit Harlan, 1940) ${ }^{11}$, Die Rothschilds (Erich Waschneck, 1940), Carl Peters (Herbert Selpin, 1941), Ohm Krüger (Hans Steinhoff, 1941) ${ }^{12}$ o Stukas (Karl Ritter, 1941). Ninguna de estas películas que integran la lista de la Fundación Murnau circuló comercialmente en Uruguay entre 1933 y $1945^{13}$.

\section{El nacional-socialismo en el Uruguay de los años treinta}

Los primeros años del nazismo en Alemania coinciden con la dictadura de Gabriel Terra en Uruguay (1933-1938). Militante del batllismo dentro del Partido Colorado, aunque, como marcan Caetano y Rilla, con «posturas moderadas en materia social que lo distanciaban del círculo más cercano a Batlle» ${ }^{14}$, Gabriel Terra (1873-1942) llega a la Presidencia en las elecciones de 1930. Muerto Batlle y Ordoñez en 1929, su camino estaba allanado. La crisis económica mundial además encontró a Terra, experto en cuestiones económicas y financieras, en el lugar y momento adecuados, como candidato del batllismo. Poco tiempo después, «en medio de rumores golpistas 


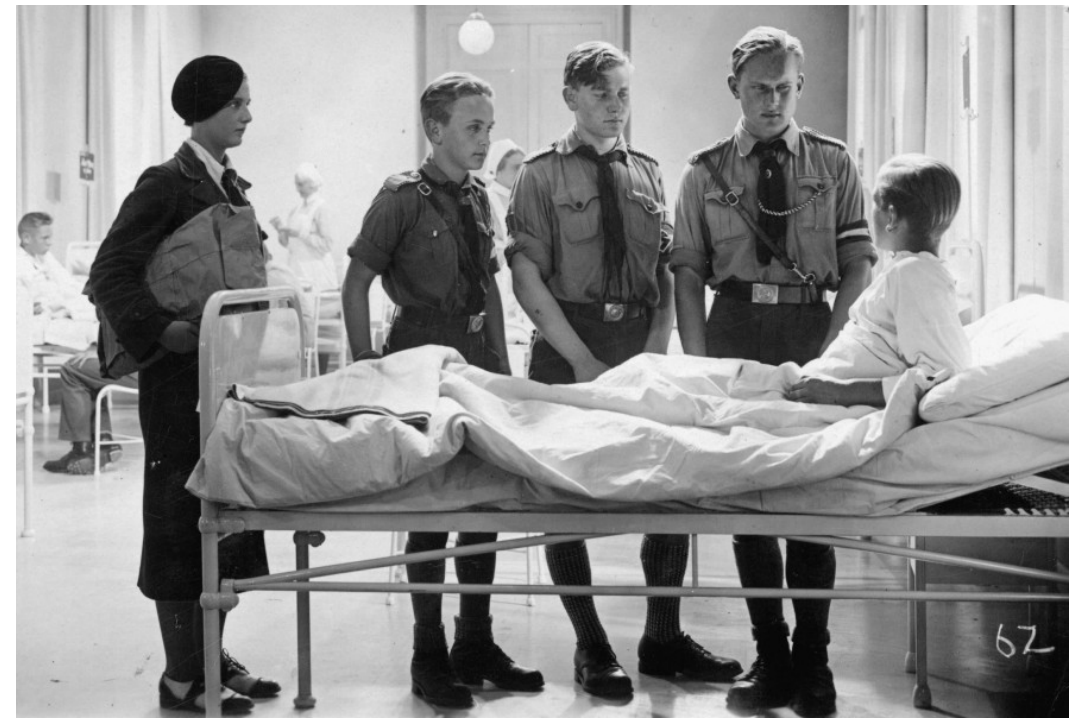

Hitlerjunge Quex (Hans Steinhoff, 1933).

y síntomas de "inquietismo" militar, con el trasfondo del ascenso del fascismo en Europa y la ola dictatorial en toda América Latina, la perspectiva de la dictadura comenzaba visiblemente a ganar espacio en el país ${ }^{15}$. El golpe de estado tuvo lugar el 31 de marzo de 1933 y en junio de ese año se elaboró el proyecto de reforma constitucional promovido por Terra que prometía «terminar con la "irresponsabilidad gubernamental"; el peligro de la "agitación" comunista estimulada desde afuera; un gobierno "ágil" y "barato" que sustituyera la "politiquería" ${ }^{16}$. Frega, Maronna y Trochón explican que si bien la reforma eliminó la experiencia del ejecutivo bicéfalo (presidente y Consejo Nacional de Administración) vigente desde la Constitución de $1919^{17}$, el régimen surgido del golpe pronto comenzaría a mostrar fisuras, debido a la convivencia de intereses políticos y económicos contrapuestos que terminaron por desgastar al bloque golpista ${ }^{18}$. La dictadura culminaría con las elecciones de marzo de 1938, tal como lo estableció la nueva Constitución impulsada por el propio Terra. El general y arquitecto Alfredo Baldomir, candidato del Partido Colorado, obtuvo la presidencia con la particularidad de la participación del voto femenino consagrado por ley en 1932, mientras el Dr. Gabriel Terra asumía «—al menos aparentementeuna actitud imparcial simbolizada en su abstención electoral» y su órgano de prensa El Pueblo también reflejaba esa postura, «ofreciendo a sus lectores en la sección "Páginas neutrales", información y propaganda de ambos candidatos»"

En materia de política exterior, Jacob señala que el Uruguay de Terra tuvo un «reordenamiento» que implicó una mejora de las relaciones con Gran Bretaña, «al hacer concesiones al principal imperialismo de la época»; también «miró con simpatía a la Alemania nazi y la Italia fascista» y «rompió relaciones con la URSS y el gobierno republicano español $»^{20}$. Las relaciones comerciales con Alemania se intensificaron en esos años. Las exportaciones uruguayas a ese país llegaron a un máximo de 22.641.279\$ en 1938, frente a \$13.303.249\$ de 1933: «en el orden energético resultó esencial la participación alemana en la construcción de la represa hidroeléctrica del Río Negro, impulsada decisivamente por Terra $»^{21}$. Dicha usina fue uno de los hitos de la administración terrista y le valió la condecoración con el «Águila de oro» del
[15] Gerardo Caetano y José Rilla, Historia contemporánea del Uruguay, p. 216.

[16] Gerardo Caetano y José Rilla, Historia contemporánea del Uruguay, p. 216.

[17] Ana Frega, Mónica Maronna e Yvette Trochón, Baldomir y la restauración democrática (19381946) (Montevideo, EBO, 1987), p. 14.

[18] Ana Frega, Mónica Maronna e Yvette Trochón, "“Frente Popular" y "Concertación Democrática". Los partidos de izquierda ante la dictadura terrista» (Cuadernos del Claeh, n. $\left.{ }^{\circ} 34,1985\right)$, p. 49.

[19] Ana Frega, Mónica Maronna e Yvette Trochón, Baldomir y la restauración democrática (19381946), p. 93.

[20] Raúl Jacob, El Uruguay de Terra. 1931-1938 (Montevideo, EBO, 1983), p. 113.

[21] Yvette Trochón y Beatriz Vidal, El régimen terrista (19331938). Aspectos políticos, económicos y sociales (Montevideo, EBO, 1993), p. 132. 
[22] Raúl Jacob, El Uruguay de Terra. 1931-1938, p. 116.

[23] Juan Oddone, El Uruguay entre la depresión y la guerra (Montevideo, FCU, 1990), p.152.

[24] Juan Oddone, El Uruguay entre la depresión y la guerra, pp. 152-153.

[25] Raúl Jacob, El Uruguay de Terra. 1931-1938, p.112.

[26] Mariana Moraes Medina, «En busca del enemigo oculto: intelectuales y revistas antinazis en el Uruguay de la Segunda Guerra Mundial» (Letral, n. ${ }^{\circ} 24$, 2020), p. 4.

[27] Mariana Moraes Medina, «En busca del enemigo oculto: intelectuales y revistas antinazis en el Uruguay de la Segunda Guerra Mundial», p. 5.

[28] Alfaro citada en: Yvette Trochón y Beatriz Vidal, El régimen terrista (1933-1938), p. 148. gobierno nazi a los ministros de Obras Públicas y de Relaciones Exteriores en $1936^{22}$. El historiador Juan Oddone, por su parte, sostiene que «las imputaciones filofascistas que se han dirigido al régimen de Terra no carecen de fundamento pero tampoco autorizan enjuiciamientos que les atribuyan una dominante inspiración durante su gestión de gobierno» ${ }^{23}$. También entiende que por más que Terra haya manifestado «en reiteradas ocasiones su adhesión al régimen de Mussolini, y más veladamente sus inclinaciones hacia el nacional-socialismo», no hubo en el Uruguay «un proyecto fascista de gobierno entre 1933 y 1938» ${ }^{24}$. Terra también desarrolló una buena relación con el Brasil de Getulio Vargas. A instancias de su gobierno, Uruguay rompería relaciones con la URSS en 1935 acusada de incidir desde la sede diplomática en Montevideo en la sublevación de la Alianza Nacional Libertadora, liderada por Luis Carlos Prestes en el país norteño.

Al mismo tiempo, mediante la política de buena vecindad promovida por Roosevelt desde que asume la presidencia en 1933, se procuraba bloquear el avance comercial e ideológico alemán en la región que se dio en los años previos al inicio de la guerra. Ese año tuvo lugar la VII Conferencia Panamericana en Montevideo donde los estados se pronunciaron en favor de los tratados bilaterales de reciprocidad y la reducción de las tarifas arancelarias de intercambio comercial. El 4 de diciembre de 1936, en línea con esta política, el presidente Roosevelt llegaría a Uruguay a bordo del acorazado Indianápolis, algo que Jacob interpreta como «un espaldarazo al terrismo» ${ }^{25}$, más allá de sus acercamientos a los regímenes alemán e italiano. Por su parte, Moraes entiende que «las no disimuladas simpatías por el pensamiento nacional-socialista y el estrechamiento de las relaciones con la Alemania nazi fueron motivo de preocupación tanto para los demócratas uruguayos como para los gobiernos de Inglaterra y Estados Unidos $\gg{ }^{26}$. En este sentido, la investigadora sostiene que el naciente panamericanismo, impulsado por la política de buena vecindad estadounidense, también dio sustento a un acercamiento de la intelectualidad con los sectores antifranquistas en España, entre otros medios, a partir de una proliferación de publicaciones antifascistas que tuvo lugar en el Uruguay de los años treinta y cuarenta del siglo XX:
Esto se comprueba en el campo cultural uruguayo, donde la implicación con la causa de la República, el fusilamiento de García Lorca y la recepción de exiliados españo- les fortaleció la identificación con la consigna «demócrata y antifascista» y determi- nó un incremento del rechazo a los discursos antisemitas y cercanos al nacionalismo fascista normalizado bajo el gobierno de Terra ${ }^{27}$.

A nivel de las relaciones diplomáticas, en 1936, el gobierno de Terra rompe con la República Española debido a la muerte de tres ciudadanas uruguayas (Dolores, María y Consuelo Aguiar) en Madrid, hermanas del vicecónsul uruguayo. A nivel de la sociedad civil, sin embargo, la guerra civil española tuvo en estas latitudes repercusiones muy grandes en apoyo de la causa republicana. A propósito de la influencia en la sociedad uruguaya, la historiadora Milita Alfaro menciona que aquella guerra:

constituyó la causa desencadenante de la mayor movilización de masas que haya protagonizado el pueblo uruguayo. Mientras una minoría más o menos vergonzante, cómodamente instalada en su casa, en el Club Español y en el gobierno, confiaba en la aviación nazifascista y en la no intervención anglofrancesa, y apostaba al triunfo de Franco, la inmensa mayoría del país colaboraba como podía para hacer realidad el «No pasarán $»^{28}$. 
A nivel de las publicaciones, Alpini señala que la circulación de la propaganda nazi en el país se daba fundamentalmente a través de los periódicos de la colectividad alemana como el Deustche Wacht («El centinela alemán»), editado a partir de 1933, y el Deustche La Plata Zeitung, que se publicaba en Buenos Aires. Algunos periódicos nacionales de inspiración filofascista (Corporaciones, Fragua, Patria, Audacia, Combate, Atención), publicados por agrupaciones de la derecha radical uruguaya, llegaron a coincidir con aquellas publicaciones en la difusión del antisemitismo y de elogios a las políticas del Tercer Reich ${ }^{29}$. Camou expresa que la afiliación de estos periódicos se hace explícita en la reproducción de artículos de revistas alemanas, así como de los discursos íntegros de Mussolini, Hitler o Goebbels en sus páginas ${ }^{30}$. Sin embargo, la historiadora advierte que las ideas del nacional-socialismo en Uruguay, durante el período de Terra, nunca impregnaron en sectores numéricamente significativos de la sociedad. Luego, bajo la presidencia de Baldomir, los representantes del nazismo serían perseguidos, con el nuevo rumbo de la política internacional alineado a los aliados. Camou explica que la adhesión de las ideas nacional-socialistas en el país, como en el resto de Latinoamérica, se produce desde la colonia alemana residente, que tuvo una alta adhesión al régimen, debido a las características de estas comunidades, integradas por individuos con poca afinidad al advenimiento de la República de Weimar y que «tendieron a mantenerse vinculados entre sí, en clubes, asociaciones culturales y religiosas, sociedades de socorro mutuo, etc., resistiéndose de esa forma a la asimilación $»^{31}$. Las actividades desarrolladas por los grupos nazis en Uruguay tuvieron libertad de acción hasta 1940, cuando se crea la Comisión Investigadora de Actividades Antinacionales de la Cámara de Representantes. Durante el período que va de 1933 a 1938 fueron realizados «conciertos, espectáculos de teatro, visitas de los famosos circos alemanes, así como actividades con un fin más marcadamente político: exhibición de películas alemanas de propaganda, conferencias y reuniones $\rangle^{32}$. La historiadora remarca también que no todos los alemanes comulgaron con esta ideología, llegando un sector a conformar una posición antinazi y democrática con órgano de prensa propio (Die Zeit [«El Tiempo»]) editado entre 1934 y 1941.
[29] Alfredo Alpini, La derecha politica en Uruguay en la era del fascismo. 1930-1940 (Montevideo, FCU, 2015), p. 27.

[30] María M. Camou, «E1 nacional-socialismo en Uruguay, 1933-1938» (Cuadernos del Claeh, n. ${ }^{\circ} 38$, octubre de 1986), p. 79 .

[31] María M. Camou, «E1 nacional-socialismo en Uruguay, 1933-1938», p. 69.

[32] María Camou, «El nacionalsocialismo en Uruguay, 1933$1938 »$, p. 77.

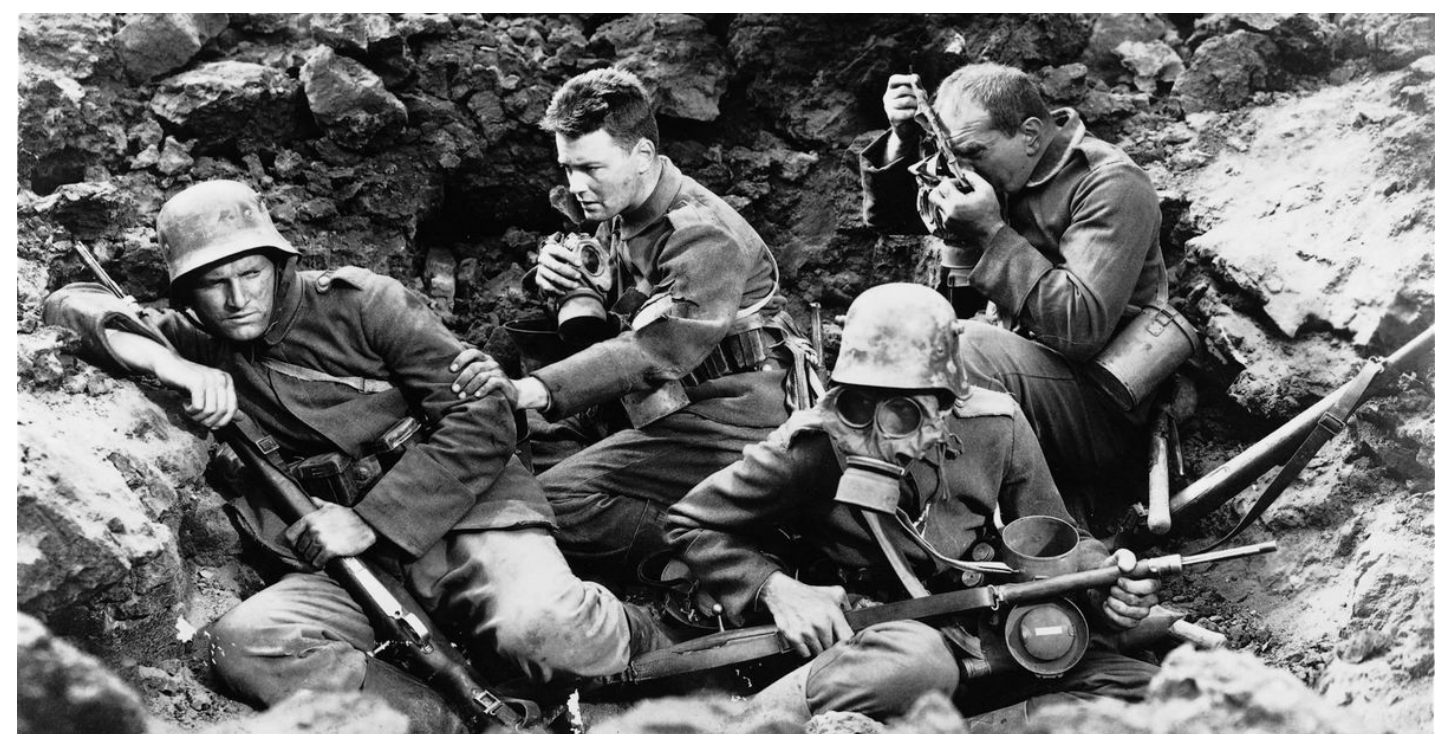

Sin novedad en el frente (All Quiet on the Western Front, Lewis Milestone, 1930). 


\section{La producción cinematográfica alemana durante el Tercer Reich}

[33] En un informe publicado por The Public Opinion Quaterly en 1939, Padover señala que Alemania lideraba en la época la producción cinematográfica en Europa. En promedio se producían 180 films por año e Inglaterra le seguía con 125 películas. Fuente: Saul K, Padover, «The German Motion Picture Today: The Nazi Cinema» (The Public Opinion Quarterly, Vol. 3, n. ${ }^{\circ}$ 1, enero de 1939), p. 142

[34] Rolf Giesen, Nazi Propaganda Films (North Carolina, McFarland, 2008), p. 5.

[35] Saul K, Padover, «The German Motion Picture Today: The Nazi Cinema», pp. 142-143.

[36] Saul K, Padover, «The German Motion Picture Today: The Nazi Cinema», p. 144.

[37] Saul K, Padover, «The German Motion Picture Today: The Nazi Cinema», p. 145.

[38] Tobias Horchscherf y Roel Vande Winkel, «Third Reich Cinema and Film Theory» (Historical Journal of Film, Radio and Television, vol. $36, \mathrm{n}^{\circ} 2$, junio de 2016), p. 197.
La relación entre el cine, la propaganda y el nazismo no nació en 1933. Como lo documenta Rolf Giesen en su libro Nazi Propaganda Films, ya en 1930 un grupo de nazis liderados por Joseph Goebbels, entonces Gauleiter del Partido Nacional Socialista en la capital alemana, boicotearon con pintadas y consignas antisemitas el estreno de la película estadounidense Sin novedad en el frente (All Quiet on the Western Front, 1930) dirigida por Lewis Milestone para la Universal Studios.

Según el historiador estadounidense Saul Padover, apenas instalados en el gobierno, los nazis procedieron a intervenir en la industria para hacerse de una buena parte del mercado de producción ${ }^{33}$. Universum Film A-G (Ufa) pertenecía mayoritariamente al empresario Alfred Hugenberg, quien había estado junto con Goebbels al frente de la operación de boicot contra Sin novedad en el frente y más tarde sería ministro de economía de $\mathrm{Hitler}^{34}$. En 1933 pasó a manos del gobierno. Terra, la segunda más grande, fue adquirida por la casa de edición Franz-Eher Verlag, propiedad del Partido Nazi. Bavaria, la tercera productora más importante, perteneciente a la Neues Deutsches Lichtspeilsyndicat (NDLS), atravesaba problemas financieros y en mayo de 1937 el gobierno se hizo de la firma. Únicamente Tobis (Tonbild Syndicat) fue capaz de soportar en los primeros tiempos la embestida y quedar en manos privadas, financiada desde Ámsterdam. A través de estas operaciones, el gobierno nazi se hizo rápidamente con el $80 \%$ de la producción cinematográfica ${ }^{35}$. En 1942 pasaron todas a estar bajo el control de Ufa.

A su vez, a través de la Reichsfilmkammer («Cámara de cine del Tercer Reich»), creada en 1934, Goebbels había instrumentado una forma de control que consistía en clasificar las películas siguiendo un orden, según las siguientes características ${ }^{36}$ : «Política y artísticamente excelente»; «Política y artísticamente útil»; «Políticamente útil»; «Artísticamente útil»; «Culturalmente útil»y, finalmente, «Educativa». Esta escala no solo determinaba la posibilidad de acceder a una mayor difusión publicitaria del film, sino también a una quita de impuestos de la Tasa de Entretenimiento, que estaba regulada en función de esas categorías. Aquellas películas que el gobierno ubicaba en el primer escalón (política y artísticamente excelente) no pagaban impuestos. Coherente con la finalidad propagandística subyacente en esta categorización, se definía como «políticamente útil» a «cualquier film que esté penetrado con el espíritu nazi ${ }^{37}$.

En el marco de una perspectiva contemporánea dentro del campo de los films studies, los investigadores Hochscherf y Winkel plantean que, lejos de encontrar una única posición acerca del propósito del cine nacional socialista y más allá de la figura central de Goebbels, existieron voces opuestas - no al régimen, por supuesto-, sino entre algunos integrantes del campo cinematográfico alemán que, de alguna manera, abren nuevas perspectivas de estudio y enriquecen la visión sobre el cine del período. Una vez censurados los textos canónicos sobre teoría del cine (Eisner, Kracauer, Balász, Eisenstein), se pone en marcha una nueva teorización sobre el cine alemán entendido como una forma de arte nacional por parte de referentes académicos, cineastas y críticos allegados al nazismo ${ }^{38}$.

A partir del análisis de una serie de artículos, libros y reflexiones de un grupo de cineastas, académicos y periodistas nucleados en torno a instituciones como la UFA Lehrschau, la Reichsfilmkammer y revistas de distribución masiva como Der Deutsche Film (publicada por la Reichsfilmkammer) y Film-Kurier, además de aquellas 
de circulación más restringida en los círculos políticos del partido nazi, Hochscherf y Winkel detectan, al menos, tres grandes posiciones en torno al deber ser del cine alemán: «si el cine podría o no ser un arte, una representación más o menos verdadera de la vida real o un entretenimiento imaginativo escapista $\rangle^{39}$.

A su vez, estos autores aclaran que es necesario tener en cuenta el contexto en el que se daba esta reflexión. En primer lugar, las ideas desarrolladas en el seno de los círculos de poder intelectual dentro del Tercer Reich en torno al cine carecían de gran originalidad, porque muchas veces se trataba de reformulaciones de anteriores teorizaciones adaptadas al momento político del Tercer Reich. En segundo lugar, precisamente por encontrarse encorsetadas en función de los objetivos del nazismo, estos planteos tampoco tenían la posibilidad de ser discutidos abierta o críticamente. No obstante, es posible imaginar que esta diversidad de las líneas teóricas en torno a lo cinematográfico, dentro del propio régimen, encuentra un correlato en la materialización de una variedad de géneros que dista de responder a una sola forma de entender el cine.

Esta diversidad le permitiría también al cine del nazismo tener una mayor apertura para la distribución internacional de sus películas. En este sentido, es interesante tener presente que tanto antes como durante el Tercer Reich, como lo demuestra la investigadora Valerie Weinstein, las comedias eran el producto más importante de los estudios alemanes:

Entre 1933 y 1945, de las 1094 películas alemanas de largometraje, 523 eran humorísticas (48 por ciento) y cada año de ese período, salvo en 1945 (con el estreno de solo 12 películas), los estudios alemanes estrenaron más comedias que cualquier otro tipo de film. En 1934, 1935, 1940, 1943 y 1944, entre el 50 por ciento (1935) y el 62 por ciento (1943) de los films producidos eran comedias ${ }^{40}$.

Weinstein señala entonces que la producción de comedias se calcula entre el 50 y el 60 por ciento del total de los films producidos en esos años. Pero a partir de esta evidencia cuantitativa la autora advierte que, lejos de vehiculizar una mirada apolítica, la comedia diseminó «de manera sutil, un proceso de definición y exclusión de lo judío» ${ }^{41}$, a través del humor, de códigos indirectos y de ausencias que fueron colaborando para que los espectadores construyeran imaginariamente «una identidad y comunidad alemana libre del judaísmo» ${ }^{42}$.

La producción de largometrajes de ficción en la Alemania nazi respondió entonces a una compleja maquinaria de producción estatal en la que estuvieron involucrados tanto actores del campo cinematográfico (teóricos académicos, críticos, cineastas, actores) como del comando político. Esta producción, dominada por la comedia, fue también la que llegó mayoritariamente a las pantallas montevideanas. Con el fin de visualizar comparativamente la distribución del cine nazi en la cartelera local, se presenta a continuación un relevamiento de todos los estrenos en Montevideo entre 1933 y 1945, agrupados por género cinematográfico. Por último, se analizará el abordaje que la crítica en Uruguay propone sobre esta producción cuya ideología nacional-socialista, siguiendo a Weinstein, estuvo latente en mayor o en menor grado en todas las películas del período. En este sentido, el artículo se propone observar los elementos analíticos éticos y estéticos que entran en juego a la hora de describir el imaginario nazi en la producción de la época por parte de la crítica de Cine Radio Actualidad, en los primeros años (1936-1937) de la revista, momento en que una crítica
[39] Tobias Horchscherf y Roel Vande Winkel, «Third Reich Cinema and Film Theory», p. 203.

[40] Valerie Weinstein, Antisemitism in Film Comedy in Nazi Germany (Bloomington, Indiana University Press, 2019), p. 4.

[41] Valerie Weinstein, Antisemitism in Film Comedy in Nazi Germany, p. 5.

[42] Valerie Weinstein, Antisemitism in Film Comedy in Nazi Germany, p. 4. 
independiente incipiente empezaba a elaborar sus primeras estrategias discursivas y la guerra aún no se advertía en el horizonte geopolítico.

\section{El cine alemán en Montevideo (1933-1945)}

Entre 1933 y 1945 se conoció un número considerable de largometrajes alemanes. De un total de ciento veintidós películas de ese origen estrenadas en Montevideo, noventa y una corresponden a producciones realizadas bajo el régimen nazi. Como se puede apreciar en el siguiente cuadro, la distribución se concentra mayormente durante los años 1936, 1937 y 1938. En 1941, en el Teatro Artigas, se produjo una situación particular: un emisario alemán, a través de un testaferro, había logrado un contrato de subarrendamiento y ese año se llegaron a estrenar diecinueve películas nazis, además del noticiero semanal de propaganda Ufa. Esto generó episodios de protestas y violencias en la sala ${ }^{43}$, en un momento en que Uruguay, a pesar de su neutralidad en la guerra, había tomado distancia de las potencias del Eje. En 1942 Uruguay rompe relaciones con Alemania, Japón e Italia y desde entonces, hasta 1946, ya no se producirán más estrenos alemanes en Montevideo.

\section{Número de largometrajes alemanes del período nazi (1933-1945) estrenados por año en Montevideo ${ }^{44}$}

[43] Osvaldo Saratsola, Función completa, por favor (Montevideo, Trilce, 2005), p. 242.

[44] Elaboración del cuadro a partir de la base de datos en línea Cinestrenos. El cine en Montevideo desde 1929. Fueron relevadas todas las películas alemanas estrenadas en Montevideo entre 1933 y 1945 . De esa lista se seleccionaron aquellas películas que fueron producidas bajo el Tercer Reich y llegaron a los cines de Montevideo.

\begin{tabular}{|c|c|c|}
\hline Año de estreno & $\begin{array}{c}\text { Número de } \\
\text { largometrajes }\end{array}$ & Cines \\
\hline 1933 & 0 & - \\
\hline 1934 & 0 & - \\
\hline 1935 & 3 & Ariel \\
\hline 1936 & 24 & $\begin{array}{c}\text { Ariel / Rex / Teatro Artigas / Estudio } \\
\text { Auditorio / Mogador }\end{array}$ \\
\hline 1937 & 22 & $\begin{array}{l}\text { Ariel / Rex / Radio City /Estudio Auditorio } \\
\text { / Ambassador }\end{array}$ \\
\hline 1938 & 16 & $\begin{array}{c}\text { Ariel / Rex / Radio City /Estudio Auditorio } \\
\text { / Ambassador }\end{array}$ \\
\hline 1939 & 4 & Estudio Auditorio / Ambassador /Andes \\
\hline 1940 & 4 & Estudio Auditorio \\
\hline 1941 & 18 & Teatro Artigas \\
\hline 1942 & 0 & - \\
\hline 1943 & 0 & - \\
\hline 1944 & 0 & - \\
\hline 1945 & 0 & - \\
\hline
\end{tabular}

Las salas Radio City, Rex Theatre, Ariel y Trocadero, eran operadas por la empresa Glücksmann, que dominaba la distribución cinematográfica. Como se observa en el cuadro, allí se exhibió cine alemán del período nazi. La filial montevideana de la empresa Glücksmann era dirigida por Bernardo Glücksmann, austríaco de origen judío que había desembarcado en la Argentina en 1905 siguiendo a su hermano 
mayor Max, fundador de la Casa Lepage de Max Glücksmann, dedicada a la venta y distribución de películas, artículos de fotografía, fonógrafos y otros productos similares. En un breve paréntesis es pertinente recordar aquí que, durante la Primera Guerra Mundial, Max Glücksmann (y su empresa) fue objeto de duras acusaciones de corte xenófobo y antisemita por parte de algunos integrantes del gremio cinematográfico en Argentina a través de la revista La Película, precisamente por distribuir películas de origen alemán. Estos ataques incluyeron listas negras de exhibidores que trabajaban con la casa distribuidora y se extendieron sistemáticamente durante varios números de la revista entre 1914 y 1918. Glücksmann terminó llevando el asunto a los tribunales y los ataques cesaron en 1919. Como observa Torello, la ofensiva contra Glücksmann se reeditó, poco tiempo después, de los dos lados del Río de la Plata, «a raíz del contrato de exclusividad que Max Glücksmann firmó, en 1921, con la productora norteamericana Paramount Pictures Corporation, hasta ese momento en manos de la Sociedad General Cinematográfica» ${ }^{45}$. El quiebre de lo que una de las revistas (Imparcial Film) llamó «pacto de honor» ${ }^{46}$ entre las dos empresas implicadas desatará nuevamente una andanada de ataques que se extenderá hasta agosto de 1922, momento en que se vuelven a calmar las aguas, definitivamente.

La competencia en la distribución de películas en Montevideo se intensificó para la firma pionera con la llegada de Metro Goldwyn Mayer Uruguay S.A. en 1934, momento que coincidió con el vencimiento del contrato que unía al estudio internacional con Glücksmann ${ }^{47}$. El remodelado Teatro Artigas, reinaugurado como sala de cine en mayo de 1934, pasó a exhibir el programa MGM, junto con las salas Azul, Paris y Novelty Theatre. En setiembre de 1936 se inauguró el cine Metro, propiedad de la empresa, con toda la pompa, 1050 butacas y autoproclamado «El templo de las estrellas», apelando a la constelación de actores y actrices que formaban parte del programa MGM.

En 1938 se crea la Compañía Exhibidora Nacional Sociedad Anónima (CENSA) con capitales uruguayos «para rivalizar con la firma Glücksmann, por entonces con un cuarto de siglo de desarrollo, dominante en Montevideo y extendiéndose a todo el país ${ }^{48}$. Además de las salas Mogador y Ambassador como recintos de primera línea, CENSA abastecería a los cines Azul, Paris, Astor y Capitol. A pesar de la consolidación de la competencia, hacia 1942 Glücksmann continuaría preservando el 44\% de la distribución en el mercado local ${ }^{49}$.

En cuanto a la producción cinematográfica en Alemania, como se ha recordado en la primera parte del artículo, no solo de propaganda se nutrían las pantallas de aquel país durante el régimen nazi. Otros géneros cinematográficos fueron estratégica y cuidadosamente impulsados desde el Ministerio de Propaganda y fueron los que obtuvieron también una mayor distribución internacional. Rafael de España, por ejemplo, expresa que la propaganda no era «el primum movens», sino que «lo que realmente quería Goebbels era una industria cinematográfica sólida cuyos productos reunieran nivel artístico y potencial taquillero» ${ }^{50}$. El mensaje llegaría solo:

Goebbels era un fanático del cine de Hollywood y sabía que los americanos introducían su Weltanschaaung a través de sus películas de esmerado acabado técnico e intérpretes de reclamo internacional. Por ello no es extraño comprobar que, al repasar los títulos producidos en Alemania bajo su mandato, aquellos directamente propagandísticos ocupan un porcentaje francamente bajo. ${ }^{51}$
[45] Georgina Torello, «Por ese terrible pulpo que todo lo quiere abarcar y dominar. Debate entre revistas especializadas a propósito de Max Glücksmann», en Actas II Simposio Iberoamericano de Estudios Comparados sobre Cine y Audiovisual: perspectivas interdisciplinarias (Buenos Aires, Editorial de la Facultad de Filosofía y Letras - UBA, 2013), pp. 10-11.

[46] Georgina Torello, «Por ese terrible pulpo que todo lo quiere abarcar y dominar. Debate entre revistas especializadas a propósito de Max Glücksmann», p.15.

[47] Osvaldo Saratsola, Función completa, por favor, p. 57.

[48] Osvaldo Saratsola, Función completa, por favor, p. 63.

[49] Osvaldo Saratsola, Función completa, por favor, p. 33.

[50] Rafael de España, «E1 cine nazi: temas y personajes» (Historia Contemporánea, n. $^{\circ} 22$, 2001), p. 151.

[51] Rafael de España, «El cine nazi: temas y personajes», 


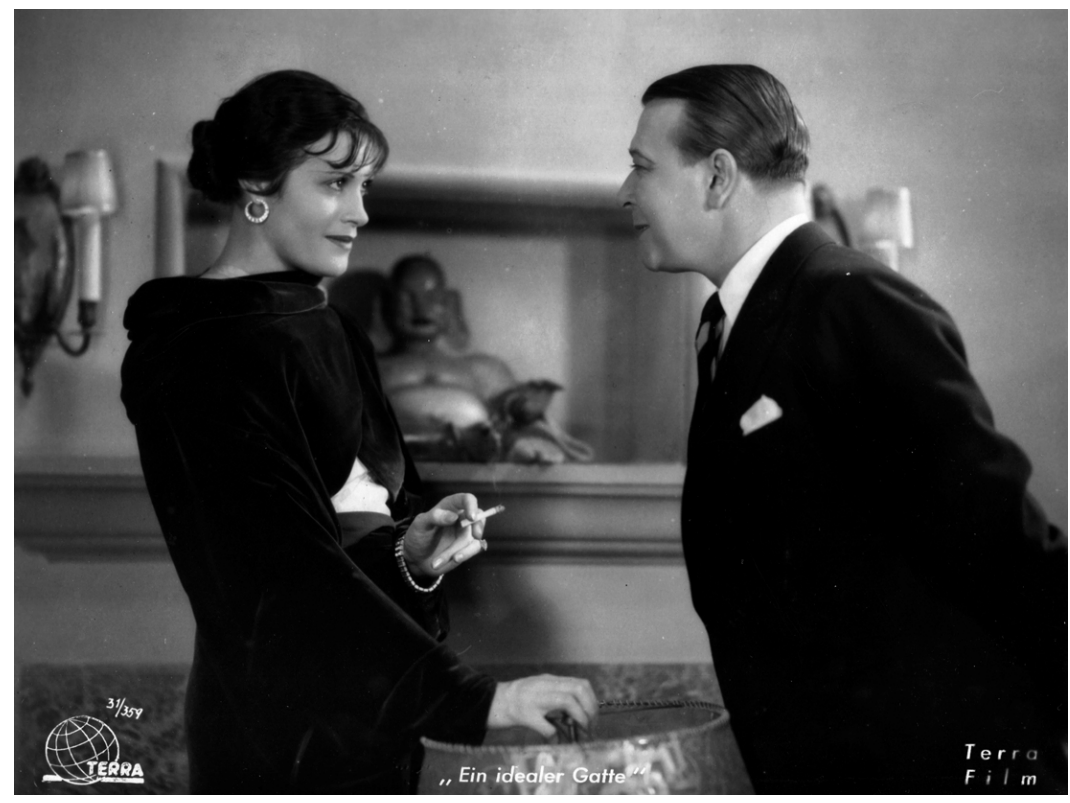

Un marido ideal (Ein idealer Gatte, Herbert Selpin, 1935).

A continuación, se presenta una lista de todas las películas alemanas de largometraje correspondientes al período del Tercer Reich, estrenadas en Montevideo entre 1933-1945, agrupadas por género, con el fin de visualizar de qué manera se reflejó la producción alemana en la cartelera local. De este modo, la idea de una producción homogénea asociada en el imaginario casi exclusivamente al cine documental de propaganda, en el caso de los largometrajes, es rebatida. La producción alemana del período se caracteriza entonces por una diversidad en lo que refiere a los géneros de ficción, que también se reflejó en las pantallas del sur. Como se verá, la presencia reiterada en estas pantallas de un grupo de realizadores emblemáticos del cine nazi, también resulta un elemento significativo para entender la producción de la época, que giraba en torno a aquellos directores de confianza del régimen. En la lista se reproducen los títulos de las películas en su lengua original (alemán) y se agrega entre paréntesis el título local (que puede no corresponder con el título que tuvieron las películas en otros países de habla hispana), año de producción y nombre del director. Se destacan en formato de negrita aquellos títulos que, una vez finalizada la guerra, fueron incluidos en la lista de films prohibidos por los aliados. Para clasificar las películas según el género, se tomó como referencia la descripción en el catálogo IMDB y, complementariamente, se recurrió a la bibliografía consultada.

Películas del período nazi estrenadas en Montevideo entre 1933 y 1945 , agrupadas por género (destacadas figuran aquellas prohibidas por los aliados).

\section{Comedia}

1- Das Schloss in Suden (Cuentan que en un castillo), 1933, Géza von Bólvary.

2- Ist mein Mann nicht fabelhaft? (El hombre que no se atrevía), 1933, Georg Jacoby. 3- Fruhjahrsparade (Desfile de primavera), 1934, Géza von Bólvary (Austria). 4- Zwischen zwei Herzen (Entre dos corazones), 1934, Herbert Selpin. 
5- Der Page vom Dalmasse-Hotel (El groom del Dalmasse Hotel), 1933, Viktor Janson.

6- Ein idealer Gatte (Un marido ideal), 1935, Herbert Selpin.

7-Les dieux s'amusent (Anfitrion, versión francesa), 1935, Reinhold Schunzel y Albert

Valentin.

8- Die unmoegliche Frau (Una mujer imposible), 1936, Johannes Meyer.

9- Mädchenjahre einer Königin (La juventud de una reina), 1936, Erich Engel

10- Gluckskinder (Alegres muchachas), 1936, Paul Martin.

11- Regine (Regina), 1934, Erich Waschneck.

12- Drei Maderl um Schubert (La casa de las tres niñas), 1936, e. W. Emo.

13- Sieben Ohrfeigen (Siete bofetadas), 1937, Paul Martin.

14- Scheidungsreise (Luna de hiel), 1938, Hans Deppe.

15- Nanon (Nanon), 1939, Herbert Maisch.

16- Der Mann, der Sherlock Holmes war (Sherlock Holmes), 1937, Karl Hartl.

17- Das Paradies der Junggesellen (El paraíso de los solteros), 1939, Kurt Hoffmann.

\section{Comedia musical / Opereta}

18- Was Frauen traumen (Lo que sueñan las mujeres), 1933, Géza von Bólvary.

19- Ich liebe alle Frauen (Amo a todas las mujeres), 1935, Carl Lamac.

20- Die blonde Carmen (Carmen rubia), 1935, Viktor Janson.

21- Die Czardasfurstin (La princesa de las czardas), 1934, Georg Jacoby.

22- Die Wirtin zum Weissen Röss'l (La hostería del caballo blanco), 1935, Frederic Zelnik.

23- Walzerkrieg (La guerra de valses), 1933, Ludwig Berger.

24- Mach'mich glucklich (La viuda soltera), 1935, Arthur Robison.

25- Zigeunerbaron (El barón gitano), 1935, Karl Hartl.

26- Petersburger Nachte (Vals imperial), 1935, e. W. Emo.

27- Wo die Lerche singt (Cuando canta la alondra), 1936, Carl Lamac.

28- Mein Herz ruft nach dir (Paso a la juventud), 1934, Carmine Gallone.

29- Der Bettelstudent (El estudiante mendigo), 1936, Georg Jacoby.

30- Das Hofkonzert (Concierto en la corte), 1936, Douglas Sirk.

31- Letzte Rose (Martha), 1936, Karl Anton.

32- Viktor und Viktoria (Una mujer de frac), 1933, Reinhold Schunzel.

33- Vergiss mein nicht (No me olvides), 1935, Augusto Genina.

34- Capriccio (Capricho), 1938, Karl Ritter.

35- Gasparone (Gasparone), 1937, Georg Jacoby.

36- Die Fledermaus (El murciélago), 1937, Paul Verhoeven.

37- Land der Liebe (El país del amor), 1937, Reinhold Schunzel.

38- Opernball (Baile en la ópera), 1939, Géza von Bólvary.

\section{Drama}

39- Kleiner Mann, was nun (El primer derecho del niño), 1933, Fritz Wendhausen.

40- Der Springer von Pontresina (El campeón de Pontresina), 1934, Herbert Selpin.

41- Schwarze Rosen (Rosas negras), 1935, Paul Martin.

42- Stradivari (Stradivarius), 1935, Géza von Bólvary.

43-Acciaio (Acero), 1933, Walter Ruttmann.

44- Der schwarze Walfisch (Fanny / La ballena negra), 1934, Fritz Wendhansen.

45- Traumulus (Soy culpable), 1935, Carl Froelich.

46- Furst Woronzeff (El principe Woronzeff, versión francesa), 1934, Arthur Robison.

47- Barcarole (Barcarola), 1935, Gerhard Lamprecht. 
48- Schlussakkord (La novena sinfonia), 1936, Douglas Sirk.

49- Das Schloss in Flandern (En un castillo de Flandes), 1936, Géza von Bólvary.

50- Mazurka (Mazurka), 1935, Willi Forst.

51- Das Madchen Irene (La chica de 16 años), 1936, Reinhold Schunzel.

52- Manja Valewska (La condesa Valewska), 1936, Josef Rovensky.

53- Peer Gynt (Peer Gynt), 1934, Fritz Wendhausen.

54- Der Tiger von Eschnapur (El tigre de Esnapur), 1937, Richard Eichberg.

55- Das indische Grabmal (La tumba India), 1937, Richard Eichberg.

56- Kinderarzt Dr. Engel (Médico de niños), 1936, Johannes Riemann.

57- Klein Dorrit (La pequeña Dorrit), 1934, Carl Lamac.

58- Zu neuen Ufern (Presidio de mujeres), 1937, Douglas Sirk.

59- Heimat (Magda), 1938, Carl Froelich.

60- La habanera (La habanera), 1937, Douglas Sirk.

61- Es war eine rauschende Ballnacht (Era una noche embriagadora), 1939, Carl Froelich.

62- Der Postmeister (Dunja, la novia eterna), 1939, Gustav Ucicky.

63- Männer müssen so sein (Mujeres entre fieras), 1939, Arthur Maria Rabenalt.

64- Verklungene Melodie (Vals de medianoche), 1938, Victor Tourjansky.

\section{Drama bélico / histórico / biográfico}

65- Schwarzer Jäger Johanna (Juana, el husar negro), 1934, Johannes Meyer.

66- Herbstmanover (Maniobras de otoño), 1935, Georg Jacoby.

67- Hundert Tage (Cien dias), 1935, Franz Wensler.

68- Das Madchen Joanna (Juana de Arco), 1935, Gustav Ucicky.

69- Stjenka Rasin (Volga! Volga!), 1936, Alexander volkoff.

70- Die Reiter von Deutsch Ostafrika (Los jinetes del África colonial), 1934, Herbert Selpin.

71- Der alte und der junge Konig (El viejo rey), 1935, Hans Steinhoff.

72- Wilhelm Tell (Guillermo Tell), 1933, Paul Heinz.

73- Weisse Sklaven (El acorazado Sebastopol), 1936, Karl Anton.

74- Manja Valewska (La condesa Valewska), 1936, Josef Rovensky.

75- Peer Gynt (Peer Gynt), 1934, Fritz Wendhausen.

76- Fanny Elssler (La bailarina vienesa), 1937, Paul Martin.

77- Unternehmen Michael (La última ofensiva del marne 1918), 1937, Karl Ritter.

78- Urlaub auf Ehrenwort (Bajo palabra de honor), 1937, Karl Ritter.

79- Hotel Sacher (Hotel Sacher), 1939, Erich Engel.

80- Signal in der Nacht (Señales en la noche), 1937, Richard Schneider-Edenkoben.

81- Robert Koch, der Bëkampfer des Todes (Roberto Koch), 1939, Hans Steinhoff.

82- Maria Ilona (Maria Ilona), 1939, Géza von Bólvary.

83- Liselotte von der Pfalz (La vida privada de Luis xiv), 1935, Carl Froelich.

84- Das Herz einer Konigin (Corazón de reina), 1940, Carl Froelich.

\section{Thriller}

85- Fahrmann Maria (La barquera María), 1935, Frank Wysbar.

\section{Documental}

86- Olimpiad I - Fest der Volker (Olimpia. Los dioses del estadio), 1938, Leni Riefenstahl. 87- Olimpiad II - Fest der Schonheit (Juventud olímpica), 1938, Leni Riefenstahl. 


\section{Aventura}

88- Der Kurier des Zaren (Miguel Strogoff, El correo del zar), 1935, Ivan Jasse.

89- Stadt Anatol (Oro negro), 1936, Victor Tourjansky.

90- Die gelbe Flagge (La bandera amarilla), 1937, Gerhard Lamprecht.

91- Der Kaiser von Kalifornien (Conquista de sangre), 1936, Luis Trenker.

92- Kautschuk (Caucho), 1938, Eduard von Borsody.

\section{Terror}

93- Der Student von Prag (El estudiante de Praga), 1935, Arthur Robison.

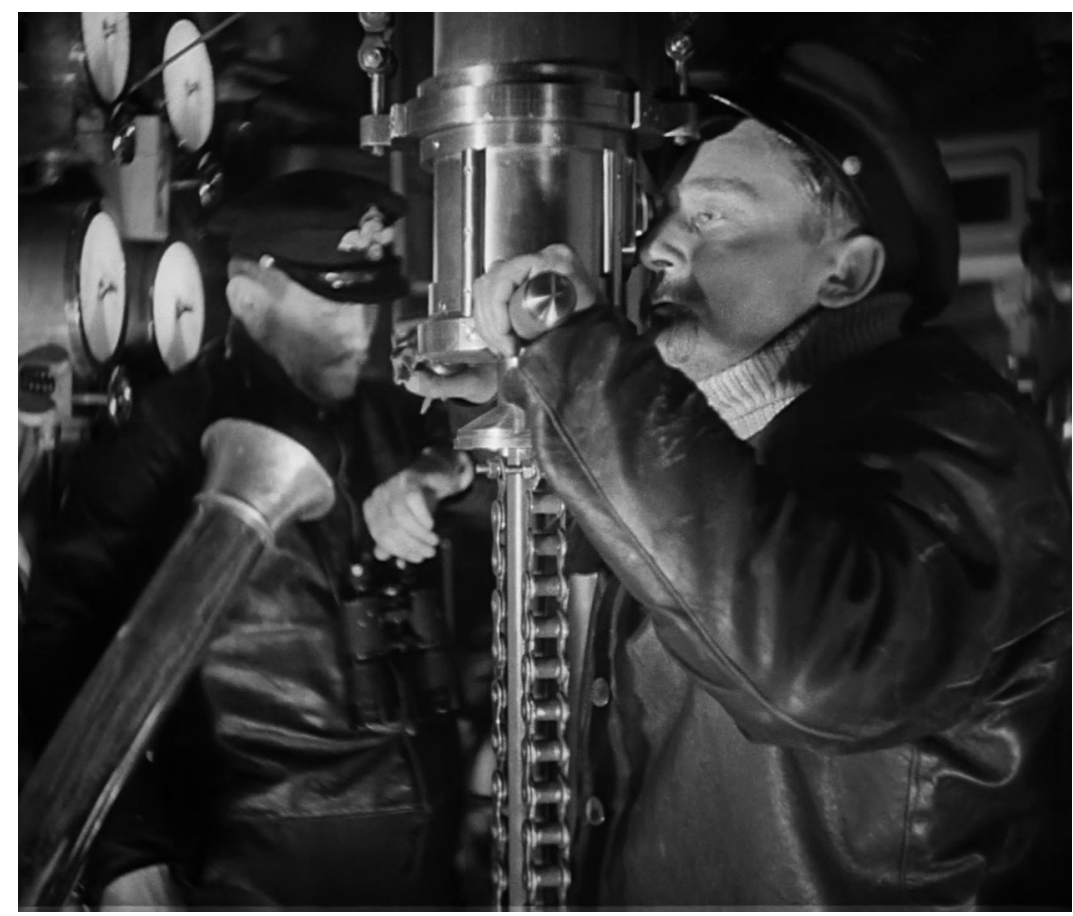

Morgenrot (Vernon Sewell y Gustav Ucicky, 1932).

En 1933 se estrenaron 18 largometrajes de origen alemán en Montevideo, pero ninguno de ellos pertenece aún al período nazi. Sin embargo, algunos autores como Giesen y Suchsland, le asignan una importancia simbólica al film Morgenrot (Vernon Sewell y Gustav Ucicky, 1932) $)^{52}$, producido durante la República de Weimar y estrenado en Uruguay el 17 de junio de 1933 en el cine Rex. La atención de estos autores reside en la temática de la película, en la presencia de Hitler en la sala el día de su estreno en Berlín en febrero de 1933 junto al propietario principal de UFA, Alfred Hugenberg, y en haber sido la primera película exhibida en los cines alemanes una vez instalado el nazismo en el poder, a pesar de no haber sido producida bajo el régimen nacional-socialista.

Morgenrot, del director Gustav Ucicky, cuenta la historia de un submarino alemán hundido por la armada británica durante la Primera Guerra Mundial. Drama bélico producido por UFA, la película presenta la lucha alemana en la guerra como un sacrificio —el capitán sacrifica su vida para salvar al resto de la tripulación-y

[52] N. del E. Estrenada en España como Crepúsculo rojo. 
[53] Hitlers ' Hollywood (Rüdiger Suchsland, 2017).

[54] Rafael de España, «El cine nazi: temas y personajes», p. 155.

[55] N. del E. Estrenada en España con el mismo título.

[56] N. del E. Estrenada en España como Órdenes secretas.

[57] N. del E. Estrenada en España como Santa Juana de Arco.

[58] N. del E. Estrenada en España como Dunia, la novia eterna. anuncia, según el realizador Rüdiger Suchsland, uno de los temas principales de la propaganda nazi: «camaradería y deber como norma fundamental», y un «colectivo de soldados como una unidad significativa, que se preparaban para sacrificar sus vidas para que la lucha continuara $\rangle^{53}$. Morgenrot es definida por Suchsland como una película que explota al máximo el mítico anhelo de morir, tan caro al nazismo y representado anualmente de forma espectacular en los multitudinarios homenajes a los muertos en el Feldherrnhalle y en la Königsplatz de Munich, liderados por el propio Hitler.

Gustav Ucicky (1899-1961), cineasta de origen austríaco que desarrolló su carrera entre Alemania y Austria, fue uno de los realizadores que se ganó la confianza del régimen, realizando, de acuerdo con España, «sustanciosas aportaciones a la propaganda nazi ${ }^{54}$. El investigador español sostiene que, junto con Gerhard Menzel como guionista, inaugurarán con el film Fugitivos (Fluchtinge) ${ }^{55}$ de 1933, el Führerprinzip, género del culto al jefe en el cine de ficción nazi. Esta película no llegó a Uruguay, pero la anterior, Morgenrot, lo hizo. Entre 1933 y 1945, fueron exhibidas cinco películas de Ucicky en el circuito montevideano: Morgenrot (1932), Corazones enemigos (Im Geheimdienst, 1931) ${ }^{56}$, Fidelidad (Hokuspokus, 1930), Juana de Arco (Das Mädchen Johanna,1935) ${ }^{57}$ y Dunja, la novia eterna (Der Postmeister, 1939) ${ }^{58}$.

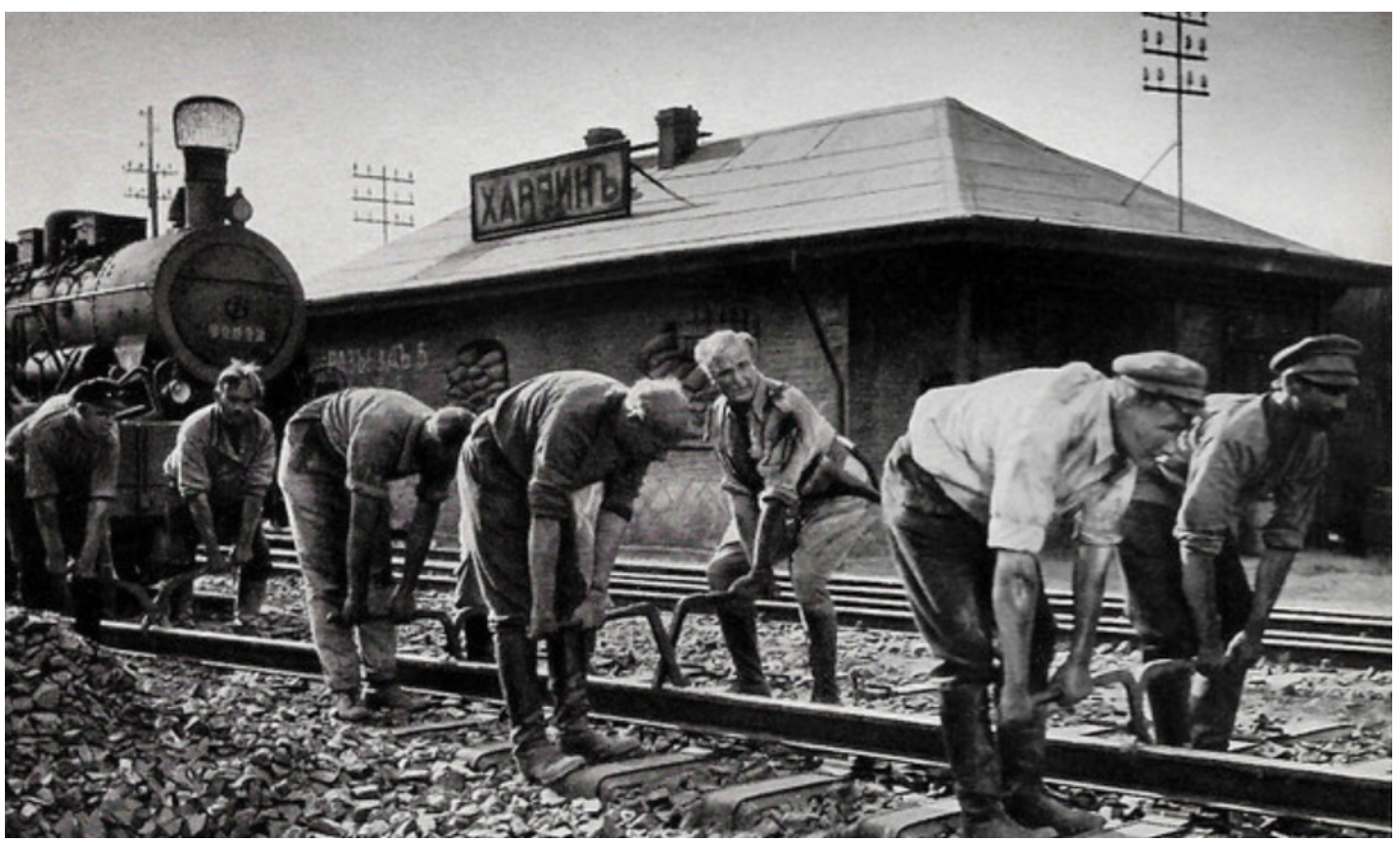

Fugitivos (Fluchtinge, Gustav Ucicky, 1933).

Con la ocupación alemana de Austria en marzo de 1938, todas las actividades cinematográficas pasaron inmediatamente al mando de la Reichsfilmkammer, algo que de hecho había comenzado mucho antes a través de la acción y presión de grupos políticos y empresariales afines al nacional-socialismo en ese país. Como establece Dassanowsky, desde los primeros lineamientos dictados para la industria nacional-socialista, se buscó estrangular la producción cinematográfica austríaca, cuyo 
principal mercado era el alemán. Ya en 1933 se había echado a andar un aceitado mecanismo de censura:

\begin{abstract}
De las catorce películas austriacas en distribución en Alemania, cinco fueron bloqueadas antes de su lanzamiento, una fue retirada de la distribución y otras tres fueron rechazadas por su «mala calidad» por parte del nuevo brazo del RMVP, la Cámara de Cine del Reich. La verdadera razón era que artistas judíos habían estado involucrados en su creación ${ }^{59}$.
\end{abstract}

Por medio del Film Agreement de 1934, la Alemania nazi prohibió la importación y exhibición de cualquier película austríaca que incluyera en el reparto o en el equipo de producción a «no-alemanes» (alemanes exiliados) o «austríacos no arios» ${ }^{60}$. En octubre de 1938, el mayor grupo de producción austríaco Tobis-Sascha es disuelto y pasa a denominarse Wien-Film A-G tras la venta de las acciones mayoritarias por parte de Oscar Pilzer al Austrian Kreditanstalt, intermediario del Reich. Wien-Film pasa a convertirse así en el quinto mayor estudio alemán, luego de UFA, Tobis, Terra y Bavaria ${ }^{61}$. La ciudad de Viena se transforma así, según explica Dassanowsky, en uno de los tres centros estratégicos en la producción cinematográfica diseñados por el ministro nazi de propaganda junto con Berlín y eventualmente Praga. En este diseño, se hace notoriamente visible la idea de Goebbels de desarrollar una industria cinematográfica a imagen y semejanza del modelo estadounidense:

Wien-Film se dedicaría a producir historias románticas, películas de opereta y musicales, como el costado más orientado al entretenimiento y más exportable de las producciones del Tercer Reich. Mientras que Ufa se centraría en los dramas, espectáculos históricos y «documentales» de propaganda. Incluso el logotipo de la nueva compañía, una clave de sol, pretendía asociar descaradamente Wien-Film con Viena como la ciudad «alemana» de la música. Las tradiciones e imágenes asociadas a Viena, incluso el dialecto, se utilizarían como muestra de la riqueza de la cultura germánica del Reich, para atraer al público de países aliados y ocupados y, lo más importante, para anexar cinematográficamente a la Viena histórica y cultural (y por extensión, a Austria) ${ }^{62}$.

Al frente de la producción del nuevo estudio Wien-Film fue nombrado el director austríaco Karl Hartl, de quien se conocieron varios films en Uruguay: La canción de Heidelberg (Ein Burschenlied aus Heidelberg, 1930) ${ }^{63}$, La condesa de Montecristo (Die Gräfin von Monte-Christo, 1931) ${ }^{64}$, El barón gitano (Zigeunerbaron, 1935) ${ }^{65}$ y Sherlock Holmes (1937) ${ }^{66}$.

El 30 de junio de 1933, poco después de la creación del Departamento de Higiene Racial, a los judíos se les prohibió oficialmente trabajar en la industria del cine. Al principio, sin embargo, dada la popularidad de algunos cineastas, se intentaron algunas medidas excepcionales como la distinción de «arios de honor». Como explica España, no muchos creyeron en este acto de gracia:

La maniobra, como es lógico, no tuvo mucho éxito: uno de los pocos que «picó» fue Reinhold Schünzel, director de comedias de gran impacto comercial — por ejemplo, las coproducciones con Francia Viktor und Viktoria (1933) y Amphytrion (1935) que por comodidad, vanidad o simple inconsciencia creyó que las autoridades del nuevo régimen le perdonarían su condición racial y en 1937 se vio obligado a emigrar también a Estados Unidos, donde tuvo que sufrir el rechazo y el desprecio de aquellos expatriados que ya habían clarificado su postura en $1933^{67}$.
[59] Robert von Dassanowsky, «Between Resistance and Collaboration: Austrian Cinema and Nazism Before and During the Annexation, 1933-1945», en Roel Vande Winkel y David Welch (eds.), Cinema and the Swastika (Hampshire, Palgrave Macmillan, 2011), p. 59.

[60] Robert von Dassanowsky, «Between Resistance and Collaboration: Austrian Cinema and Nazism Before and During the Annexation, 1933-1945», p. 59.

[61] Sabine Hake, Popular Cinema of the Third Reich (Austin, University of Texas Press, 2001), p. 150 .

[62] Robert von Dassanowsky, «Between Resistance and Collaboration: Austrian Cinema and Nazism Before and During the Annexation, 1933-1945», p. 62.

[63] N. del E. Estrenada en España como Estudiantes.

[64] N. del E. Estrenada en España como La condesa de Monte Cristo.

[65] N. del E. Estrenada en España con el mismo título.

[66] N. del E. Estrenada en España con el mismo título.

[67] Rafael de España, «El cine nazi: temas y personajes», p. 165. 


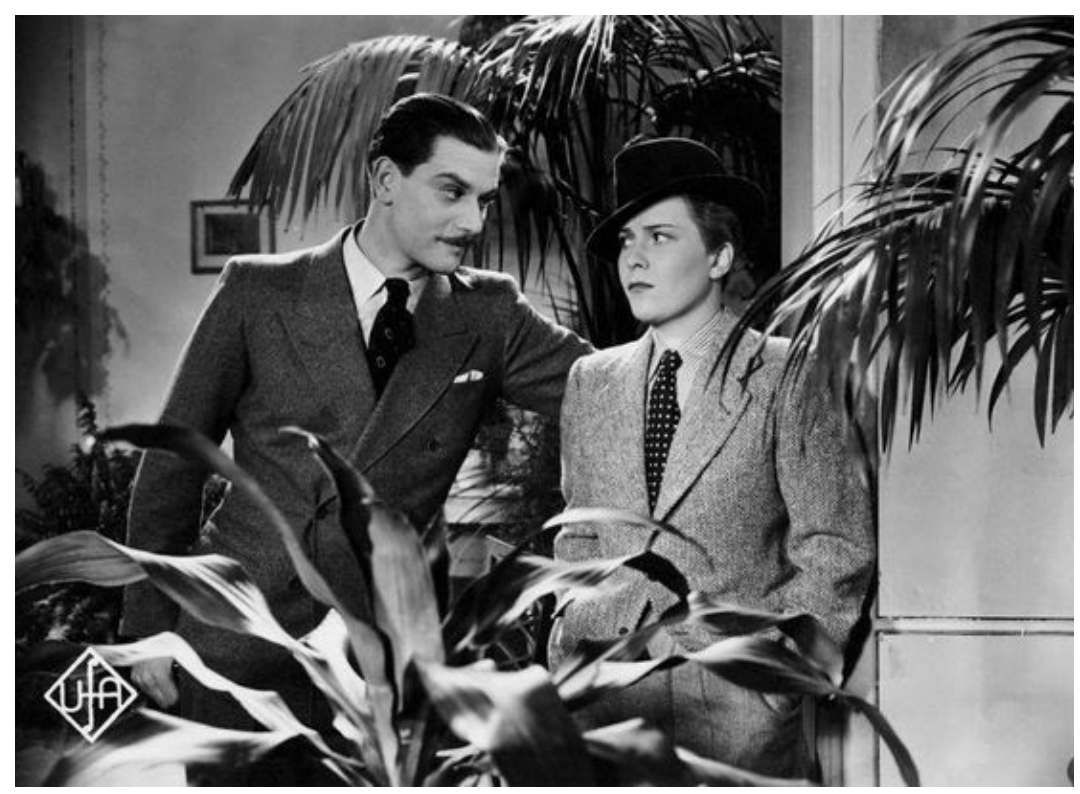

Una mujer de frac (Viktor und Viktoria, Reinhold Schünzel, 1933).

Precisamente de Schünzel llegaron a Uruguay, entre otras, esas dos comedias. Amphytrion se estrenó en 1936 en el cine Rex y Viktor und Viktoria ${ }^{68}$ se exhibió en 1938 bajo el título Una mujer de frac, en el cine Rex. También del mismo director, se exhibieron en el circuito montevideano, Ronny (1931), Cómo se lo digo a mi marido (Wie sag' ich's meine Mann?, 1932), La chica de 16 años (Das Mädchen Irene, 1936) ${ }^{69} \mathrm{y}$ El pais del amor (Land der Liebe, 1937).

En abril de 1941, cuando los cines en Montevideo ya no exhibían películas alemanas desde el estreno de El país del amor (1937) de Reinhold Schünzel en noviembre del año anterior, se produce un desembarco de películas nazis en el cine Teatro Artigas, que se fueron exhibiendo a razón de dos o tres por mes, hasta diciembre. En total se exhibieron 19 estrenos alemanes en 1941, debido a la explotación de la sala por parte de un emisario encubierto del régimen nazi. Una de las películas que se presentaron en ese ciclo fue Caucho (Kautschuk, 1938) ${ }^{70}$, del director Eduard von Borsody. Se trata de un trabajo que se ubica en una extraña categoría, ya que desde una producción alemana se exalta el imperialismo británico, en una ficción de carácter comercial sobre un espía inglés, en una fazenda [hacienda] en Brasil, que pretende robar una semilla de la planta de caucho para terminar con el monopolio de

[68] N. del E. Estrenada en España como Él... es ella.

[69] N. del E. Estrenada en España como Mamá se casa.

[70] N. del E. Estrenada en España como Caucho alarma en la selva.

[71] Rafael de España, «El cine nazi: temas y personajes», p. 160. este producto. La acción se desarrolla en 1876 e invierte el clásico binomio moral el bien contra el mal: en este caso, el espía ladrón es presentado como un valiente al servicio de la corona, mientras el hacendado brasileño que defiende sus intereses comerciales es un inescrupuloso machista y tirano. En este sentido, España expresa: «Hasta el principio de la guerra no aparece en el cine alemán una imagen negativa de los ingleses, a los que los nazis consideraban una especie de "primos lejanos" con nexos raciales más o menos intensos $\rangle^{71}$. Recién en 1941, señala este autor, aparecen dos películas con fuerte mensaje antibritánico: Ohm Krüger, de Hans Steinhoff, y Carl Peters, de Herbert Selpin; ambas se encuentran en la lista de películas prohibidas elaborada por la Fundación Murnau. 


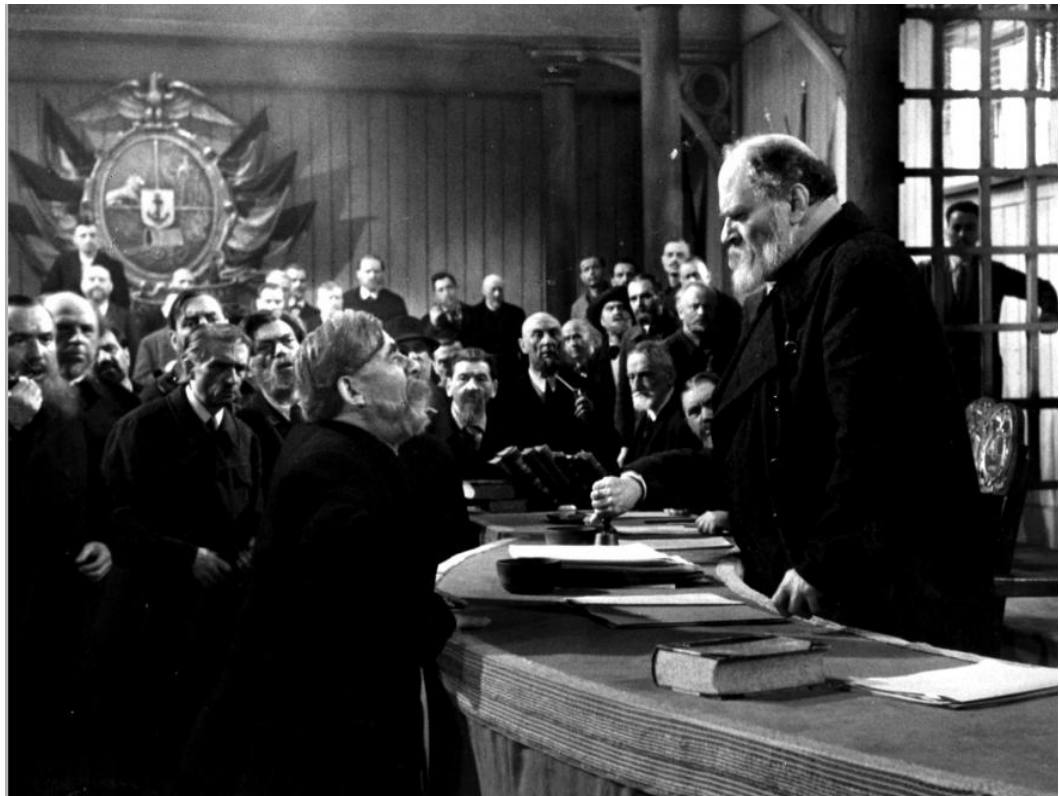

Ohm Krüger (Hans Steinhoff, 1941).

Las dos últimas no fueron exhibidas en el circuito montevideano. Sin embargo, de estos realizadores se conocieron varias películas en los cines de la capital. De Hans Steinhoff se exhibieron $\boldsymbol{E l}$ viejo rey (Der alte und der junge König, 1935) ${ }^{72}$ y Roberto Koch (Robert Köch, der Bekämpfer des Todes, 1939) ${ }^{73}$. Steinhoff es, además, el realizador de Hitlerjunge Quex, una dura película de propaganda, también prohibida actualmente que, si bien no se exhibió en Montevideo entre 1933 y 1945, fue programada décadas después en la Cinemateca Uruguaya en 1977. Finalmente, otro de los directores que frecuentaron las pantallas de Montevideo fue Herbert Selpin, de quien se exhibieron cuatro películas durante el período analizado: Entre dos corazones (Zwischen zwei Herzen, 1934), El campeón de Pontresina (Der Springer von Pontresina, 1934), Un marido ideal (Ein idealer Gatte, 1935) y el film de propaganda Los jinetes del África colonial (Die Reiter von Deutsch Ostafrika, 1934) ${ }^{74}$.

\section{La primera recepción crítica del cine del Tercer Reich en Uruguay a través de la revista Cine Radio Actualidad (1936-1937)}

En los años 1936 y 1937 se estrenaron en Montevideo cuarenta y seis películas alemanas producidas por el Tercer Reich. Son los dos años de mayor afluencia de películas de ese origen al circuito de salas comerciales. También se trata del primer contacto firme con el cine nazi a nivel local, ya que el año anterior (1935) habían llegado apenas tres títulos. Como se aprecia en el listado de estrenos, además, el gran porcentaje de películas que se exhibieron corresponden a largometrajes de ficción-comedia y drama- y solo se estrenaron dos documentales, realizados por Leni Riefenstahl.

Para tener una primera aproximación a la recepción crítica, se expondrá el abordaje que la revista Cine Radio Actualidad propone de algunas películas. El criterio de selección es, en primer lugar, temporal. Se escogieron películas exhibidas durante los primeros dos años de la revista (1936-1937), período que coincide con la llegada del
[72] N. del E. Estrenada en España como El rey soldado.

[73] N. del E. Estrenada en España como Roberto Koch, el vencedor de la muerte

[74] N. del E. Estrenada en España como Héroes en África. 
cine nazi a las pantallas montevideanas. En segundo lugar, se seleccionaron aquellos títulos que integraron la lista de películas prohibidas elaborada por los aliados luego de la Segunda Guerra, por considerar que pueden estar ideológicamente más comprometidas con el imaginario nacional-socialista. De este modo, se podrá apreciar mejor el discurso que una incipiente crítica independiente en el país empezaba a desarrollar ante la aparición de la producción cinematográfica del Tercer Reich.

Creada en 1936 por René Arturo Despouey y Emilio Dominoni Font con el nombre Cine Actualidad, la revista pasa a denominarse Cine Radio Actualidad a partir del número 12 cuando incorpora una nueva sección radial. De distribución semanal, alcanzó una rápida aceptación y se convirtió en un magazine cultural de referencia para un público lector que en los 40 y 50 ya asistía masivamente al cine. Con un tratamiento gráfico en el que se destacaba la imagen como puerta de entrada al texto, la publicación se incorporaba al circuito de lo que Beatriz Sarlo, al estudiar las narraciones semanales para un público medio y popular, define como «un modo estético de literatura cotidiana» ${ }^{75}$ caracterizado por «trabajar con la atención puesta sobre la función recreativa, emplear materiales lingüísticos, ideológicos y literarios que no rebasen el habitus de sus lectores» ${ }^{76}$. En este sentido, la declaración de principios que emana del editorial del primer número de Cine Actualidad, ilustrado en la tapa con una foto de página entera de Fred Astaire en el film Sombrero de copa (Top Hat, Mark Sandrich, 1935), es elocuente de un interés por captar a un público que no imaginaban elitista:

Cine Actualidad no será una hoja adusta, ni hablaremos en ella sus redactores con la voz campanuda y estentórea de los «magisters». No. Por vías diferentes y en épocas distintas nos hemos ganado, cada uno de nosotros, la atención del público sin necesidad de abandonar para ello la sonrisa propia de las gentes jóvenes y entusiastas, que no creen ni siquiera necesario, para convencer, impresionar comenzando una crónica de este modo: «Me decía una vez Fedor Ozep...» o «Aquella tarde en que tomé el té con Gloria Swanson» ${ }^{77}$.

[75] Beatriz Sarlo, El imperio de los sentimientos (Norma, Buenos Aires, 2000), p. 206.

[76] Beatriz Sarlo, El imperio de los sentimientos, p. 206.

[77] Editorial, «Las palabras obligadas» (Cine Actualidad, n. ${ }^{\circ}$ 1, abril de 1936), p. 3.

[78] Editorial, «Las palabras obligadas», p. 3.

[79] Hugo Rocha, «Retrato de un crítico adolescente. Los comienzos en Cine Radio Actualidad» (El País Cultural, n. ${ }^{\circ} 891,1^{\circ}$ de diciembre de 2006), p. 6.

[80] Editorial, «Las palabras obligadas», p. 3 .
Una dosis educativa en lo que concierne a la apreciación cinematográfica, pero en un lenguaje llano, que posibilitara su comprensión a un público lector que termina, entre tanta oferta de nuevos medios gráficos, «por no saber qué ir a ver, y cuando hay una película por encima del nivel corriente, cómo verla» ${ }^{78}$, es lo que se plantea Cine Actualidad en otro pasaje del editorial. La aparición en 1936 de una revista dedicada a la crítica independiente de cine, de la mano de reconocidos intelectuales como Emilio Dominoni Font y René Arturo Despouey, significó, en palabras del crítico Hugo Rocha, «una bienvenida innovación en el ambiente cultural uruguayo de $1936 »^{79}$. La independencia de los intereses comerciales y empresariales también era destacada en el editorial de su primer número:

Empresa de orden puramente lírico aparecerá, cuando pueda, con avisos totalmente ajenos al gremio, si es que hubiera de solicitarlos o comprometer por ellos la imparcialidad de su opinión: y siempre con dinero de sus editores y fundadores. Por eso sale tan modesta y pobrecita de ropajes. No será una revista de relumbrón, sino una hoja valientemente escrita para un público consciente, si bien posiblemente desorientado por montones de gacetillas oficiosas en un medio donde todo, o casi todo lo que se publica sobre cine está comprado y regido por comerciantes; donde apenas 
se alza, sin apoyo ni ecos, alguna voz aislada y donde prima la confusión y el $\operatorname{caos}^{80}$. Hasta ese momento, las páginas cinematográficas de los diez diarios existentes en Montevideo se nutrían de anuncios y comunicados suministrados por los exhibidores. Cine Radio Actualidad sentó las bases de una nueva crítica que había comenzado a esbozarse a principios de los años treinta con el trabajo de pioneros como José María Podestá y el mismo Despouey y es considerada, en cierto modo, como la precursora del semanario Marcha y la Generación del 45 en Uruguay.

A partir de algunos textos críticos publicados durante los dos primeros años de la revista, se presentará el análisis que propusieron los críticos fundadores de la publicación sobre algunos de los films producidos bajo el Tercer Reich. Concretamente se seleccionaron aquí algunas reseñas de Despouey y Dominoni sobre Juana, el húsar negro (1934), El viejo rey (1935), Rosas negras (Schwarze Rosen, Paul Martin, 1935) ${ }^{81}$, Cien días (Hundert Tage, Franz Wensel, 1935), Stradivarius (Géza von Bólvary, 1935), Juana de Arco (1935) y Los jinetes del África oriental (1937). Interesa aquí acercar una mirada al discurso de la recepción crítica de la época en torno al cine nazi y comprender las herramientas analíticas - las formas de acercarse al objeto- a las que apela una crítica independiente en ciernes para dar forma al análisis de los films.

Juana, el húsar negro (1934) se estrenó el 31 de julio de 1936 en el Teatro Artigas. De su director, Johannes Meyer, también se exhibieron Bajo falsa bandera (Unter falscher Flagge, 1932) en el cine Rex en 1933; El sueño de Viena (Traum von Schönbrunn, 1933), producida por UFA en Austria, en el cine Ariel en 1936; y Una mujer imposible (Die unmögliche Frau, 1936) en el cine Rex, durante la temporada 1937. Sobre Juana, el húsar negro, el crítico René Arturo Despouey proponía en Cine Actualidad una breve reseña, con una lectura de corte irónico y notoriamente confundido con el género del personaje encarnado por Marianne Hoppe:

\begin{abstract}
Trescientos actos de película alemana que pasará a la historia como la primera producción totalmente incomprensible de la cabeza a los pies que se haya pasado por nuestras pantallas. No se sabe quiénes son los adversarios de Napoleón, ni quienes ayudan al duque de Brunswick, ni dónde están los ejércitos, ni por qué se declaró la guerra. Ni siquiera llega a aclararse si la protagonista es un hombre disfrazado de mujer, como parece en un principio, o una mujer en «travesti» de varón, como cree advertir uno al final, en que Marianne Hoppe adquiere cierto aire ambiguo y ciertas resemblanzas [sic] con Katharine Hepburn que al fin la disculpan un poco ${ }^{82}$.
\end{abstract}

En las líneas que siguen, Despouey vuelve a resaltar la extensión del film, señalando que los «trescientos actos (así me lo parecieron a mí al menos) pudieron haber sido reducidos a seis» ${ }^{83}$, destaca la presencia lateral de dos actores (Gustav Gründgens y Luise Ullrich) a su entender desaprovechados y finalmente lamenta otra vez la confusa narración de la anécdota histórica sobre la que se asienta el film.

En cuanto a la anécdota, uno de los temas históricos favoritos de la propaganda nazi, porque ofrecía tierra fértil para la exaltación del nacionalismo, fue el de la guerra de liberación contra Napoleón. Juana, el húsar negro se inscribe en este género, aunque el film, como sugiere el investigador italiano Virgilio Ilari, planteaba una historia de aventuras «sin excesivas pretensiones políticas» ${ }^{84}$. Con producción de Terra, cuenta las aventuras de espionaje y amor de una joven de buena familia que en 1809 termina uniéndose, encubierta con ropa de hombre, a los húsares negros leales al duque de Brunswick refugiado en Bohemia, que combate
[81] N. del E. Estrenada en España con el mismo título.

[82] René A. Despouey, «Juana, el húsar negro» (Cine Actualidad, n. ${ }^{\circ} 10,8$ de agosto de 1936), p. 5.

[83] René A. Despouey, «Juana, el húsar negro», p. 5.

[84] Virgilio Ilari, «Verbotene Filme I Kriegsfilme del Terzo Reich». 


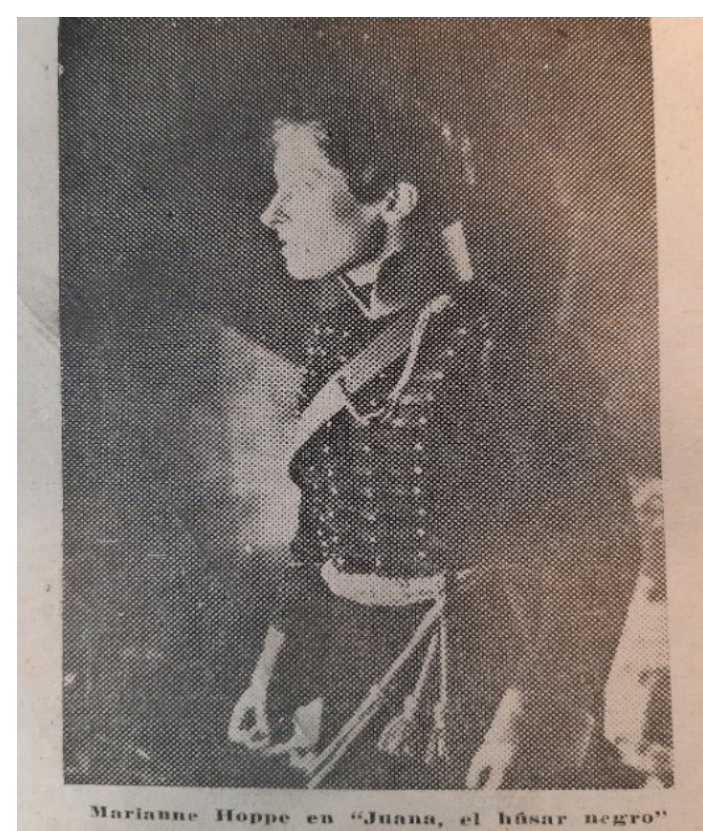

Marianne Hoppe en Juana, el húsar negro (Schwarzer Jäger Johanna, Johannes Meyer, 1934). Cine Actualidad, n.으 10 (ANIP - Sodre).

[85] Virgilio Ilari, «Verbotene Filme I Kriegsfilme del Terzo Reich».

[86] Virgilio Ilari, «Verbotene Filme I Kriegsfilme del Terzo Reich».

[87] Virgilio Ilari, «Verbotene Filme I Kriegsfilme del Terzo Reich».

[88] Emilio Dominoni, «Una loa a la Prusia y al régimen prusiano de antaño: El viejo rey» (Cine Actualidad, n. ${ }^{\circ} 11,29$ de agosto de 1936), p. 38

[89] Emilio Dominoni, «Una loa a la Prusia y al régimen prusiano de antaño: El viejo rey»», p. 38.

[90] Emilio Dominoni, «Una loa a la Prusia y al régimen prusiano de antaño: El viejo rey», p. 38.

[91] Emilio Dominoni, «Una loa a la Prusia y al régimen prusiano de antaño: El viejo rey», p. 38

[92] Emilio Dominoni, «Una loa a la Prusia y al régimen prusiano de antaño: El viejo rey»», p. 38. contra el enemigo que quiere transformar el ducado en un Departamento francés ${ }^{85}$.

Dentro del género histórico que, en este caso, exalta el Führerprinzip, El viejo rey (1935) de Hans Steinhoff fue estrenada en Montevideo el 11 de agosto de 1936 en el cine Ariel, una sala céntrica operada por la compañía Glücksmann. Ubicada por algunos autores dentro del conjunto de películas del Tercer Reich dedicadas a glorificar la figura de Federico II de Prusia, la película de Steinhoff luego fue censurada por los alia$\operatorname{dos}^{86}$. De acuerdo con Ilari, este film es una muestra característica del cine desde una perspectiva totalitaria, en la que se «reescribe el pasado y representa el presente en función exclusivamente de la política, con el fin de despertar al pueblo y movilizarlo para la lucha final contra el enemigo interno y la conspiración internacional ${ }^{87}$. En El viejo rey, el actor Werner Hinz interpreta a un joven Federico, mientras Emil Jannings interpreta a su cruel padre Guillermo de Prusia.

La crítica de Emilio Dominoni en Cine Actualidad titulada «Una loa a la Prusia y al régimen prusiano de antaño: El viejo rey» hace foco en la carrera y el logrado trabajo de Emil Jannings en su rol de Guillermo.

Así, se destaca la presencia del célebre actor en el film por considerarlo «el intérprete siempre dispuesto, el más propicio, cuando en los talleres alemanes se necesita un actor de carácter que sortee dificultades fundamentales de un personaje» ${ }^{88}$. Acerca de la presencia del actor en Alemania, donde, en palabras de Dominoni, tuvo que «buscar apoyo» una vez que en los Estados Unidos «el cine que lo encumbrara lo rechazó», se explica (o justifica), curiosamente, debido a que «se trata una de las pocas figuras del gran cine alemán de antes que por no contar con ascendientes judíos ha subsistido en "studios" berlineses»"

En cuanto a la realización, el crítico entiende que el film está bien logrado en su parte técnica y es elogioso con el trabajo de cámara al que califica «de calidad superior $\gg^{90}$. Por su parte, el episodio histórico que da sustento a la trama se centra, según la reseña, en el trabajo de Emil Jannings y «sirve exclusivamente para pintar un carácter» ${ }^{91}$. Aunque define al argumento de moralmente «despreciable», en referencia a las enseñanzas de un rey hacia su hijo, al que convierte en un autómata sin sentimientos, el crítico no repara en el uso que se hace de la historia por parte del cine nacional-socialista. Una última reflexión acerca de la crueldad de la monarquía prusiana lleva a trazar algún paralelismo, aunque tímido, con los tiempos que corrían, sin advertir intereses propagandísticos en el film. En este sentido sugiere que: «Todo tiende a justificar el por qué la monarquía prusiana llegó a ser poderosa y temida. Todo recoge del pasado histórico un solo brochazo certero, aunque odioso, e innecesario de recordar en los momentos actuales $»^{92}$.

Rosas negras es una película alemana de 1935 del director austrohúngaro Paul Martin (1899-1967). Su protagonista, Lilian Harvey, nacida en Londres de padre alemán y madre inglesa, formó junto con Willy Fritsch una de las más célebres parejas del cine europeo romántico, debido al éxito que tuvieron las operetas producidas por Ufa en los 


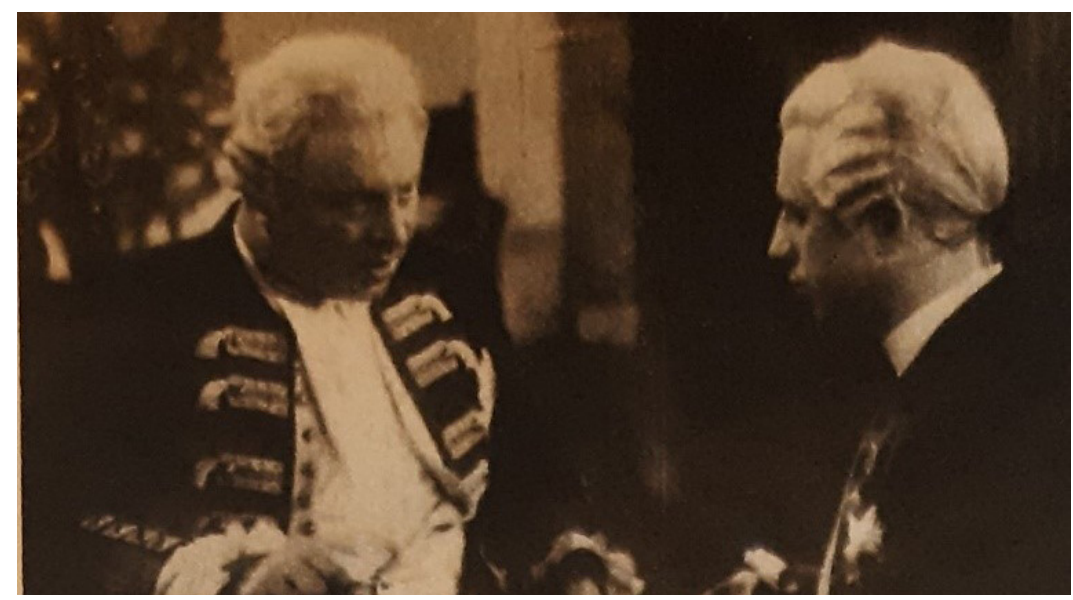

Escena de El viejo rey (Der alte und der junge König, Hans Steinhoff, 1935). Cine Actualidad, n.으 11 (ANIP-Sodre).

primeros años treinta con el advenimiento del sonoro y que, generalmente, se hacían en tres idiomas (alemán, francés, inglés). Rosas negras fue muy popular en Alemania porque significó el regreso de Harvey al cine alemán y su reencuentro con Fritsch en un film, luego de un breve pasaje por Hollywood. La película tuvo sus versiones inglesa y francesa, dirigidas por el mismo director, protagonizadas por Harvey, pero con protagonistas masculinos diferentes: Esmond Knight en la versión inglesa (Black Roses, 1936) y Jean Galland en la francesa (Roses noires, 1935) interpretaron al personaje del revolucionario finlandés Pavo Collin. En Uruguay se exhibió la versión francesa.

A pesar de ser la actriz favorita de Hitler, lejos de comulgar con la ideología nacional-socialista, Harvey tuvo que escapar de Alemania en 1939 hacia Francia y luego los Estados Unidos, una vez que su popularidad se apagó, por ayudar a escapar del país a personas perseguidas por el régimen. Esta película es un drama histórico, género al que no estaba asociada esta actriz de comedias ligeras populares, que narra la historia de una bailarina rusa (interpretada por Harvey), que sacrifica su vida para salvar la de su amante revolucionario, un escultor finlandés, que combatía a las fuerzas del zar en Finlandia durante la era del Imperio ruso. Fue uno de los films alemanes prohibidos por los aliados en 1945 luego de la Segunda Guerra.

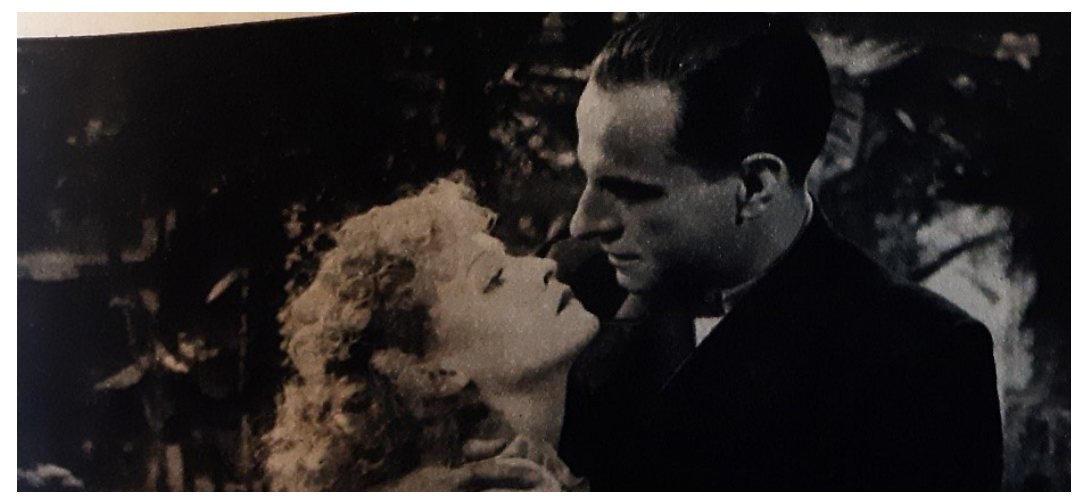

Lilian Harvey y Jean Galland en Rosas negras (Schwarze Rosen, Paul Martin, 1935). Cine Actualidad, n. 11 (ANIP-Sodre). 
La película se estrenó en Montevideo el 14 de agosto de 1936, en el cine Ariel. Una crítica de Dominoni ponía énfasis, precisamente, en la falta de dominio del drama por parte de una actriz con otro tipo de características. Ya el título de la reseña, «En Rosas negras intenta ponerse dramática Lillian Harvey», da una pista sobre el marco de presentación del análisis, centrado en la carrera y el trabajo de la actriz. Luego de comentar su «poca efectiva andanza por el país del dólar» ${ }^{93}$ y una malograda despedida en Hollywood con la película Un sueño en la Costa Azul, su regreso a Europa, a juzgar por el crítico Uruguay, no parece haber sido el mejor:

Rosas negras nos trae la nueva Lillian Harvey. Angulosa, fría, desgreñada, con signos de anemia en su figura y en su juego, la actriz pizpireta, graciosa, simpática de otrora, ha dado paso en ella a la excesiva estilización de una mujer que ya parece vieja para actuar como dama joven. Y si grande y lamentable es el cambio, más lamentable aún es el error de desviar el personaje cinematográfico de Lillian Harvey, queriendo adaptarlo a un papel que nada tiene que ver con el temperamento y modalidad de la actriz ${ }^{94}$.

Algunos rasgos destacables de la película tienen que ver, según Dominoni, con «algunos pasajes descriptivos de costumbres, las fiestas populares con las fogatas de los amados, o las tomas de los «ballets» en que Lillian Harvey coquetea con el baile de punta» ${ }^{95}$. Más allá de esos aciertos, la versión francesa que llegó a las pantallas montevideanas tampoco parece haber logrado un buen nivel interpretativo por parte del actor Jean Galland, descrito de manera irónica como un «excelente actor cómico en los momentos de mayor tensión dramática» ${ }^{96}$.

Stradivarius es una película del año 1935 realizada por Géza von Bolváry para Tobis, de la que también existe una versión alemana y una versión francesa, con diferentes elencos. De Géza von Bolváry, director de origen austríaco que trabajó para el Tercer Reich, se exhibieron en Uruguay trece películas entre 1933 y 1945. Stradivarius se estrenó el 26 de setiembre de 1936 en el cine Rex, dentro del programa Glucksmann. El violín que da nombre a la película cuenta con la particularidad de traerle mala suerte a su propietario. Ambientada antes, durante y después de la Primera Guerra, cuenta la historia de amor entre un oficial húngaro que hereda un

[93] Emilio Dominoni, «En Rosas negras intenta ponerse dramática Lillian Harvey» (Cine Actualidad, n. ${ }^{\circ} 1129$ agosto de 1936), p.39.

[94] Emilio Dominoni, «En Rosas negras intenta ponerse dramática Lillian Harvey», p. 39.

[95] Emilio Dominoni, «En Rosas negras intenta ponerse dramática Lillian Harvey», p. 39.

[96] Emilio Dominoni, «En Rosas negras intenta ponerse dramática Lillian Harvey», p.39.

[97] Stradivarius» (Variety, n. ${ }^{\circ} 8$, 6 de noviembre de 1935), p.21. Stradivarius y una joven italiana en Budapest. El oficial es también un violinista que decide dedicarse a la música, pero (producto de la mala suerte) estalla la guerra, debe partir al frente y lógicamente los amantes deben separarse. En el frente de batalla es herido gravemente y hecho prisionero, pero es atendido por un médico que le salva la vida y finalmente lo ayuda a reencontrarse con su amada.

De acuerdo con una reseña publicada en Variety $^{97}$, la versión francesa está muy bien lograda, con planos de gran nivel técnico y una música adecuada en las escenas de guerra, así como por el trabajo de los actores (Pierre-Richard Willm, Edwige Feuillère y Jean Galland), todos elementos que evitan hacer caer el tema en la banalidad. Al Uruguay llegó la versión alemana, con otros intérpretes (Gustav Fröhlich, Sybille Schmitz y Albrecht Schoenhals). Esta película también fue prohibida por los Aliados luego de la Segunda Guerra.

En lo que concierne a la crítica en Cine Radio Actualidad, René Arturo Despouey propone un abordaje predominantemente estético y (una vez más) irónico, de una película de la que el crítico rescata más que nada la música, interpretada por Mischa Elman a quien define como «el protagonista de esta lenta y cuidada biogra- 


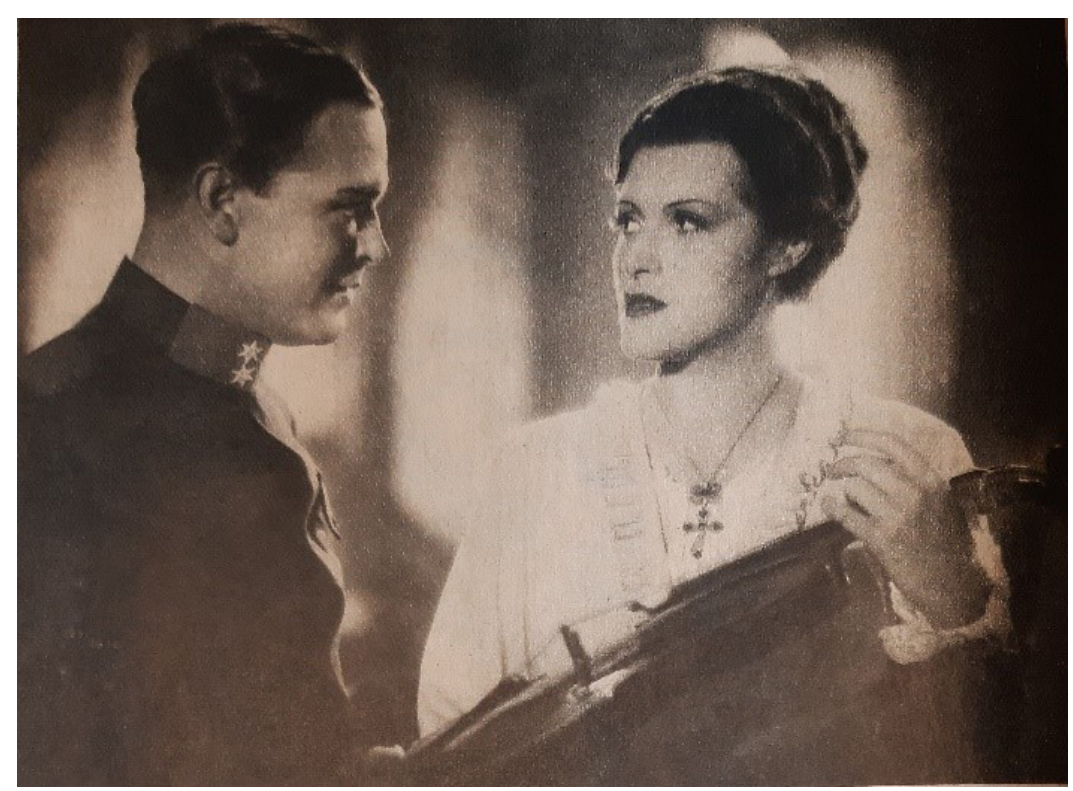

Gustav Fröhlich y Sybille Schmitz en Stradivarius (Stradivari, Géza von Bólvary, 1935). Cine Radio Actualidad, n. 16 (ANIP - Sodre).

fía de un violín». En los papeles protagónicos, Despouey sugiere que «se defiende sin esfuerzo Gustav Froelich y mejora su maquillaje y su juego Sybille Schmitz, vampiresa positivamente cómica en Un marido ideal y hoy regenerada heroína $\gg^{98}$, en referencia a un film anterior de la actriz. En cuanto a la historia, «la seriedad excesiva y la escasa materia romántica del film, hacen que la parte contemporánea haya de defenderse a fuerza de "ambiente", de fidelidad increíble en la evocación de esas ciudades en tiempos de guerra ${ }^{99}$. De su realizador señala que «Herr Géza von Bólvary, que hasta ahora se empleara casi siempre en discreteos románticos, decidió probarnos con Stradivarius que él también sabía, a su vez, meter la nariz en alguna vida privada», pero que «decidió que esa vida privada fuera la de un violín y no la de un monarca o un arquetipo» ${ }^{100}$.

Cien días, realizada en 1935 por el director Franz Wensel, es una coproducción entre Alemania e Italia. Está basada en una obra teatral del autor Giovacchino Forzano, en colaboración con el propio Mussolini, sobre la derrota de Napoleón, que servía de fondo para exaltar la figura del líder fascista. Una versión italiana llevó el título original Campo di maggio ${ }^{101}$. En Uruguay se estrenó la versión alemana, el 10 de octubre de 1936, en uno de los ciclos de la sala Estudio Auditorio.

En la reseña de Cien días, Dominoni reparará, esta vez, en la intención propagandística del film, a diferencia del análisis sobre El viejo rey, en el que esos aspectos eran ignorados. La coautoría de Mussolini, muy probablemente, haya influido en esta nueva mirada, menos inocente que las que hasta ahora se han presentado aquí, tal como se aprecia en el fragmento siguiente:

Para apoyar su concepto imperialista de nuevo César, una de las cosas que ha hecho el múltiple y politécnico Benito Mussolini, al dar rienda suelta a sus veleidades literarias, es escribir en colaboración con el dramaturgo Giovacchino Forzano, una pieza
[98] René A. Despouey, «La vida privada de un violín, en Stradivari» (Cine, Radio Actualidad, . $^{\circ}$ 16, 2 de octubre de 1936), p. 14.

[99] René A. Despouey, «La vida privada de un violín, en Stradivari», p. 14.

[100] René A. Despouey, «La vida privada de un violín, en Stradivari», p. 14.

[101] Rafael de España, «El cine nazi: temas y personajes», p. 157. 


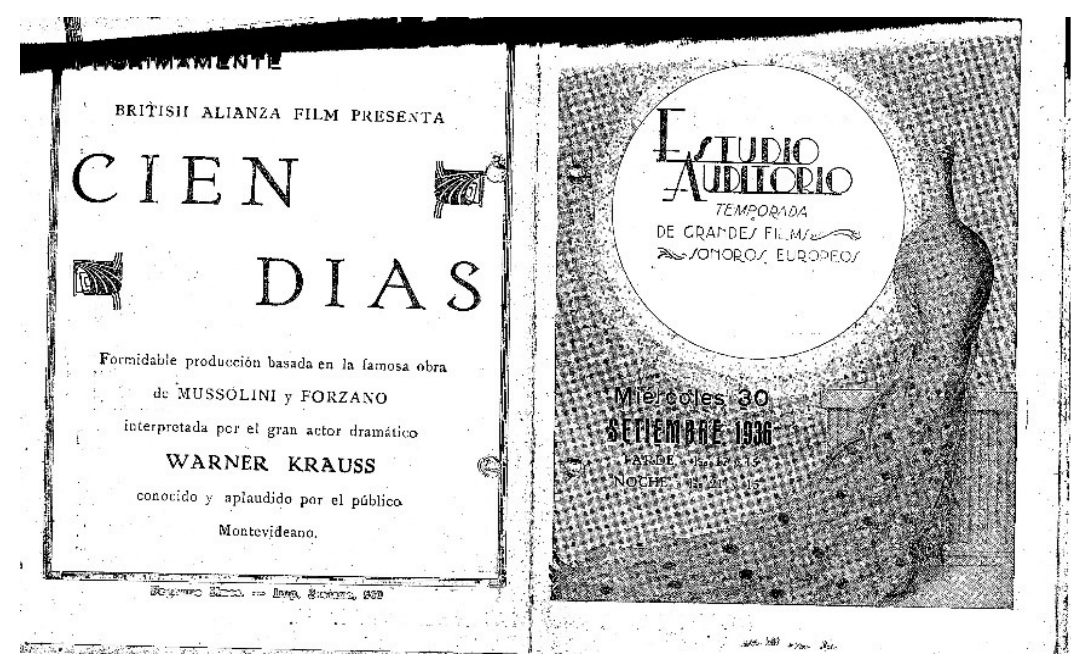

Cien días (Hundert Tage, Franz Wensel, 1935) en el programa de la sala Estudio Auditorio (Fuente: ANIP-Sodre).

de teatro, «Cien días», bien recibida en los escenarios alemanes, porque seguramente su relato de una de las partes más ricas en anécdotas de la agitada existencia de Napoleón complacía también, por razones obvias, al «Führer» Adolf Hitler ${ }^{102}$.

La crítica también se detiene en el pobre trabajo del actor Werner Krauss que, casualmente, había estado el año anterior en Montevideo presentando esa obra en el Teatro Solís. Sobre los aciertos en el tratamiento estético del film, el crítico expresa que «el registro fotográfico de esta aventura napoleónica tiene brillantez en algunas escenas - contadas- y especialmente en relatos de batalla» ${ }^{103}$, al tiempo que señala deficiencias en lo narrativo que dejan al descubierto una intención ideológica:

Discusiones de congreso, estrategias militares y cuestiones de política estadual no son precisamente las más adecuadas para complacer a los públicos de esta película con asunto de italianos, atmósfera francesa e interpretación alemana, evidenciada, más que en todo, en ese «iVivée la Franche!» que le obliga a decir al coro napoleónico para recordarnos que la película viene de «studios» puestos bajo la supervigilancia nazi ${ }^{104}$.

Con Juana de Arco (1935) de Gustav Ucicky, estrenada en Montevideo el 29 de enero de 1937, el crítico Emilio Dominoni Font abandona aquella mirada naif que había caracterizado, salvo en Cien días, los otros textos reseñados, para pasar definitivamente a advertir y denunciar los aspectos propagandísticos utilizados por el régimen. Bajo el título «Juana de Arco, gran realización al servicio de una deleznable tendencia», en Cine Radio Actualidad el crítico comienza la reseña en este tono:

El fascismo, como el comunismo, como todos los movimientos extremos, ha visto en el cine un objeto magnífico de propaganda. Desde la expulsión de los artistas judíos, Alemania nos está bombardeando, bajo la supervisión inmediata de los consejeros del «Führer», una cantidad de notables películas y de indignantes carteles al mismo tiempo. Fue hace unos meses «El viejo rey» y es ahora «Juana de Arco», realización
[102] Emilio Dominoni, «Cien dias» (Cine Radio Actualidad, . $^{\circ}$ 18,16 de octubre de 1936), p. 4.

[103] Emilio Dominoni, «Cien dias», p. 4.

[104] Emilio Dominoni, «Cien días», p. 4. 
de Gustav Ucicky donde se tergiversan todos los episodios de la intervención de la doncella en la guerra franco-inglesa y se sacan de ella las más sorprendentes y conversadas conclusiones en apoyo al nacionalsocialismo ${ }^{105}$.

En el plano del análisis estético del film, la realización es muy elogiada por estar «estupenda de atmósfera, de severidad en vestiduras y en desnudos interiores» y lleva al crítico a encontrar influencias de La pasión de Juana de Arco (La passion de Jean d'Arc, 1928) de Carl T. Dreyer por su realización plástica. La reseña se despliega así en dos dimensiones; una que denuncia una flagrante propaganda en la que «se proyecta la sombra de Hitler» y otra que elogia los aspectos estéticos logrados por su fotografía y la narración de algunas escenas en las que «queda registrada la angustia de la guerra y el dolor del pueblo mediante un estratégico reparto de luces, planos y volúmenes en un criterio pictórico independiente de lo interpretativo» ${ }^{106}$.

Por último, Los jinetes del Africa colonial (1934) de Herbert Selpin, fue estrenada el 28 de octubre de 1937 en la sala Estudio Auditorio del Sodre. En este film, se exalta la resistencia de los colonos alemanes comandados por Paul Emil von Lettow-Vorbeck (1870-1964) en las colonias africanas, en vísperas de la Primera Guerra. En Cine Radio Actualidad, el crítico Dominoni dedica una breve reseña, en la que comienza ubicando allí la trama:

Tendiendo a favorecer, de acuerdo a su procedencia, la actuación de un cuerpo militar alemán en el África Oriental, la película ofrece una vez más el melodramático asunto de dos amigos que al estallar la guerra, por ser de distinta nacionalidad, se ponen frente a frente en calidad de enemigos ${ }^{107}$.

En el transcurso de la película y con el trasfondo de la guerra suceden otras acciones que tienen que ver con lo que Dominoni describe como «el sacrificio de un muchacho por una causa que seguramente no comprende» o «la abnegación de una mujer que se expone a ser condenada por espía al proporcionar informaciones a su esposo», algo que el crítico considera como algo «inseparable de estos temas bélicos» ${ }^{108}$, pero que en realidad ya eran figuras recurrentes del cine de ideología nazi. Como lo expresa el investigador italiano Virgilio Ilari, «la nostalgia de las colonias africanas y, en general, de la proyección alemana en el mundo» ${ }^{109}$, fue uno de los temas recurren-

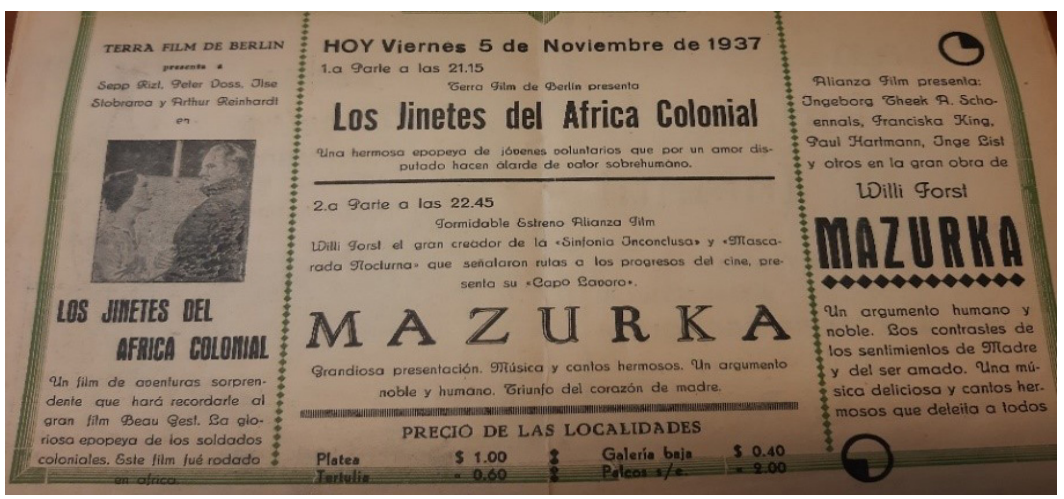

Programa de la sala Estudio Auditorio (5/11/1937). Los jinetes del África colonial (Die Reiter von Deutsch Ostafrika, Herbert Selpin, 1934), presentada como "La gloriosa epopeya de los soldados coloniales» (Fuente: ANIP-Sodre).
[105] Emilio Dominoni, «Juana de Arco, gran realización al servicio de una deleznable tendencia» (Cine Radio Actualidad, n. $^{\circ} 34,5$ de febrero de 1937), p. 13.

[106] Emilio Dominoni, «Juana de Arco, gran realización al servicio de una deleznable tendencia», p. 13 .

[107] Emilio Dominoni, «Los jinetes del Africa colonial» (Cine Radio Actualidad, n. ${ }^{\circ} 73,5$ de noviembre de 1937), p. 17

[108] Emilio Dominoni, «Los jinetes del Africa colonial», p. 17.

[109] Virgilio Ilari, «Verbotene Filme I Kriegsfilme del Terzo Reich». 
tes en el cine del Tercer Reich, particularmente explotado en sus films por Herbert Selpin (1902-1942), director de Alarma en Pekin (Alarm in Peking, 1937) y Carl Peters, películas actualmente prohibidas en Alemania que no conocieron distribución en Uruguay en esos años.

\section{Comentarios finales}

A mediados de los años treinta, el cine comenzaba a ser un negocio rentable en Montevideo. En 1934, la firma Metro Goldwin Mayer decide radicarse en la ciudad y desvincularse del contrato que lo unía a la primera empresa del país dirigida por Bernardo Glücksmann. Las salas de cine comenzaban entonces a modificar la arquitectura del centro de la ciudad y, en 1936, sostiene Saratsola, la inauguración del cine Metro «marcaba la cancha y establecía un antes y un después en la calidad de los cines locales ${ }^{110}$. En 1937 se contaban aproximadamente seis millones de espectadores en 85 salas de cine, en una ciudad de 692.000 habitantes. A fines de la Segunda Guerra, el número de espectadores ascendería a más de diez millones anuales, en una ciudad con 84 salas en el año 1945.

Como se pudo observar en el relevamiento de estos estrenos, el cine documental de propaganda (de largometraje) llegó de la mano de Leni Riefenstahl, de quien se exhibió Olympia I - Fest der Völker y Olimpia II - Fest der Schönheit (1938), estrenadas en Montevideo en 1939. Las películas de propaganda nazi actualmente prohibidas en Alemania no llegaron a estrenarse comercialmente en Uruguay en aquella época. El cine nazi que llegó a las pantallas de esta ciudad rioplatense estuvo marcado principalmente por comedias, dramas, aventuras y adaptaciones históricas o biografías de personajes míticos. No por ello, como se expuso siguiendo a Valerie Weisntein, dejaban de ser vectores de una ideología antisemita latente.

La mayor circulación de estrenos alemanes se produce en 1936, 1937, 1938 y 1941. En 1942 Uruguay rompe relaciones con Alemania, Japón e Italia y desde entonces, hasta 1946, ya no se producirán más estrenos alemanes en Montevideo. La exhibición de esas películas se produjo mayoritariamente en los cines Ariel, Rex y Radio City, operados por Glücksmann. En la sala Estudio Auditorio, que aún no era operada cinematográficamente por el SODRE, también se estrenaron algunos films alemanes del período nazi durante esos años, que llegaron a través de otras distribuidoras menores.

En cuanto a la recepción de estas películas en la revista Cine Radio Actualidad, dentro de un corpus exploratorio de textos seleccionados, se aprecia un abordaje cuyo análisis recae principalmente en las dimensiones estéticas y actorales de los films. Desde el punto de vista estético, se evidencia en los escritos una preocupación por la incidencia de las posiciones de cámara, la luz, el «registro fotográfico», la música, la recreación realista de los ambientes y de las escenas de guerra. En lo que refiere al énfasis en lo actoral, aquí emerge una característica de la crítica propia de una época en la que el realizador aún no ocupaba el lugar sagrado que le dieron en los años cincuenta los Cahiers du Cinéma, y la atención en un film radicaba en el nombre de los actores y actrices, sus carreras y el dominio de ciertos géneros con que se los solía identificar. Cuando la actriz o el actor se apartaban de los parámetros más o menos conocidos, corrían el riesgo de caer en la ridiculización o la ironía por parte del crítico.

[110] Osvaldo Saratsola, Función completa, por favor, p. 38 .
Por último, la aproximación estética que dominaba las apreciaciones críticas solía olvidar, muchas veces, tanto el contexto político y social en el que los films de 
ficción eran producidos, como el mensaje latente que podían llegar a contener. A pesar de algunos abordajes que pueden parecer inocentes, la mirada apolítica es abandonada en los casos en que la propaganda se hace evidente y entonces es denunciada abiertamente por el crítico. El caso de la crítica de Juana de Arco, en 1937, empieza a dar señales de un giro en la apreciación de los films. Sin embargo, a pesar de estas excepciones obvias, en líneas generales, los films no son analizados en estos primeros dos años de acercamiento al cine nazi desde la complejidad de la maquinaria de producción del régimen. El contexto de producción de las películas y su dependencia del Ministerio de Propaganda está prácticamente ausente del análisis en las reseñas. Las películas son abordadas de forma aislada, como obras independientes unas de otras, haciendo mayoritariamente atención en sus aspectos estéticos, sin percibir que, aun en el caso de las comedias, responden a una estrategia cuidadosamente planeada de propaganda antisemita, racista y chauvinista.

\section{FUENTES}

Anáforas. Publicaciones periódicas del Uruguay.

$<$ http://anaforas.fic.edu.uy/jspui/>

Cinestrenos. El cine en Montevideo desde 1929.

$<\mathrm{http}: / / \mathrm{www}$.uruguaytotal.com/estrenos/>

Internet Archive.

$<$ https://archive.org/>

\section{FUENTES PRIMARIAS}

Colección Revista Cine Radio Actualidad. Depositada en el Archivo Nacional de la Imagen y la Palabra, SODRE, Uruguay.

\section{REFERENCIAS HEMEROGRÁFICAS}

\section{Cine Radio Actualidad}

Despouey, René A., «Juana, el húsar negro» (Cine Actualidad, n. ${ }^{\circ}$ 10, 8 de agosto de 1936), pp. 5-6.

Despouey, René A., «La vida privada de un violín, en Stradivari» (Cine Radio Actualidad, n. ${ }^{\circ}$ 16, 2 de octubre de 1936), p. 14.

Dominoni, Emilio, «En Rosas negras intenta ponerse dramática Lillian Harvey» (Cine Actualidad, n. ${ }^{\circ}$ 11, 29 de agosto de 1936), p. 39.

Dominoni, Emilio, «Una loa a la Prusia y al régimen prusiano de antaño: El viejo rey» (Cine Actualidad, n. ${ }^{\circ}$ 11, 29 de agosto de 1936), p. 38.

Dominoni, Emilio, «Cien Días» (Cine Radio Actualidad, n. ${ }^{\circ}$ 18, 16 de octubre de 1936), p. 4.

Dominoni, Emilio, «Juana de Arco, gran realización al servicio de una deleznable tendencia» (Cine Radio Actualidad, n. ${ }^{\circ}$ 34, 5 de febrero de 1937), p. 13.

Dominoni, Emilio, «Los jinetes del África colonial» (Cine Radio Actualidad, n. ${ }^{\circ}$ 73, 5 de noviembre de 1937), p. 17. 
Editorial, «Las palabras obligadas» (Cine Actualidad, n. ${ }^{\circ}$ 1, abril de 1936), p. 3.

El Pais

Rocha, Hugo, «Retrato de un crítico adolescente. Los comienzos en Cine Radio Actualidad» (El País Cultural, n. ${ }^{\circ}$ 891, Montevideo, $1^{\circ}$ de diciembre de 2006), pp. 6-7.

Variety

«Stradivarius», (Variety, n. ${ }^{\circ}$ 8, 6 de noviembre de 1935), p. 21.

\section{BIBLIOGRAFÍA}

AlPINI, Alfredo, La derecha politica en Uruguay en la era del fascismo. 1930-1940 (Montevideo, FCU, 2015).

Caetano, Gerardo y Rilla, José, Historia contemporánea del Uruguay. De la colonia al siglo XXI (Montevideo, Claeh / Fin de siglo, 2016).

CAmou, María, «El nacional-socialismo en Uruguay, 1933-1938» (Cuadernos del Claeh, n. ${ }^{\circ}$ 38, octubre de 1986), pp.67-83.

DASSANOWSKY, Robert von, «Between Resistance and Collaboration: Austrian Cinema and Nazism Before and During the Annexation, 1933-1945», en Roel Vande Winkel y David Welch (eds.), Cinema and the Swastika (Hampshire, Palgrave Macmillan, 2011), pp. 58-71.

De EspaÑa, Rafael, «El cine nazi: temas y personajes» (Historia Contemporánea, n. $\left.{ }^{\circ} 22,2001\right)$, pp. 151-178.

Frega, Ana, MARONNA, Mónica y Trochón, Yvette, «"Frente popular” y «Concertación Democrática». Los partidos de izquierda ante la dictadura terrista» (Cuadernos del Claeh, n. $\left.{ }^{\circ} 34,1985\right)$, pp. 49-62.

_, Baldomir y la restauración democrática (1938-1946) (Montevideo, EBO, Col. Temas del siglo XX, 1987).

Giesen, Rolf, Nazi Propaganda Films (North Carolina, McFarland, 2008).

HaKe, Sabine, Popular Cinema of the Third Reich (Austin, University of Texas Press, 2001).

HochsCherf, Tobias y VANDE Winkel, Roel, «Third Reich Cinema and Film Theory» (Historical Journal of Film, Radio and Television, vol. 36, n. ${ }^{\circ}$ 2, junio de 2016), pp. 190-213.

ILARI, Virgilio, «Verbotene Filme I Kriegsfilme del Terzo Reich» (Conference Paper, mayo de 2015). Disponible en: https://www.researchgate.net/publication/ 274989203_Verbotene_Filme_I_Kriegsfilme_del_Terzo_Reich.

JACOB, Raúl, El Uruguay de Terra. 1931-1938 (Montevideo, EBO, 1983).

JENKINs, Mark, «Why 'Forbidden Films' Remain Officially Locked Away» (National Public Radio. Movie Reviews, 14 de mayo de 2015). Disponible en: https://www.npr. org/2015/05/14/405966208/why-forbidden-films-remain-officially-locked-away.

Kelson, John F. y Kenneth R. M. Short (eds.): Catalogue of Forbidden German Feature and Short Film Productions: Held in Zonal Film Archives of Film Section (Information Services Division, Control Commission for Germany. Trowbridge, Flicks Books, 1996).

Moraes Medina, Mariana, «En busca del enemigo oculto: intelectuales y revistas antinazis en el Uruguay de la Segunda Guerra Mundial» (Letral, n. ${ }^{\circ} 24$, julio de 2020), pp. 1-21. 
Oddone, Juan, El Uruguay entre la depresión y la guerra (Montevideo, FCU, 1990).

Padover, Saul K., "The German Motion Picture Today: The Nazi Cinema» (The

Public Opinion Quarterly, vol. 3, n. ${ }^{\circ}$ 1, enero de 1939), pp. 142-146.

SARATSOla, Osvaldo Saratsola, Función completa, por favor (Montevideo, Trilce, 2005).

SARLo, Beatriz, El imperio de los sentimientos (Buenos Aires, Norma, 2000).

TORELlo, Georgina, «Por ese terrible pulpo que todo lo quiere abarcar y dominar. Debate entre revistas especializadas a propósito de Max Glücksmann», en Actas II Simposio iberoamericano de estudios comparados sobre cine y audio visual: perspectivas interdisciplinarias (Buenos Aires, Editorial de la Facultad de Filosofía y Letras. UBA, 2013), pp. 10-23.

Trochón, Yvettey Vidal, Beatriz, El régimenterrista (1933-1938). Aspectos políticos, económicos y sociales (Montevideo, EBO, 1993).

Weinstern, Valerie, Antisemitism in Film Comedy in Nazi Germany (Bloomington, Indiana University Press, 2019).

\section{PELÍ́CULAS}

Verbotene Filme (Felix Moëller, 2013).

Hitlers' Hollywood (Rüdiger Suchsland, 2017).

Recibido: 1 de junio de 2020

Aceptado para revisión por pares: 18 de septiembre de 2020

Aceptado para publicación: 21 de enero de 2021 